\title{
Protein Activity Sensing in Bacteria in Regulating Metabolism and Motility
}

\author{
Alejandra Alvarado ${ }^{1,2+}$, Wiebke Behrens ${ }^{3 t \ddagger}$ and Christine Josenhans ${ }^{1,2,3 *}$ \\ ${ }^{1}$ Max von Pettenkofer-Institute, Ludwig Maximilian University of Munich, Munich, Germany, ${ }^{2}$ German Center for Infection \\ Research (DZIF) Partner Site Munich, Munich, Germany, ${ }^{3}$ Institute of Medical Microbiology and Hospital Epidemiology, \\ Hannover Medical School, Hanover, Germany
}

\section{OPEN ACCESS}

Edited by:

Enrica Pessione,

University of Turin, Italy

Reviewed by:

Jin Zhou,

Tsinghua University, China

Hans-Georg Koch,

University of Freiburg, Germany

Maria Gabriella Giuffrida,

Italian National Research Council

(CNR), Italy

${ }^{*}$ Correspondence:

Christine Josenhans

josenhans@mvp.Imu.de;

Christine.Josenhans@mvp.Imu.de

tThese authors have contributed equally to this work

${ }^{\ddagger}$ Present address: Wiebke Behrens,

Leibniz Institute DSMZ-German Collection of Microorganisms and Cell

Cultures GmbH, Braunschweig,

Germany

Specialty section:

This article was submitted to Microbial Physiology and Metabolism,

a section of the journal

Frontiers in Microbiology

Received: 04 October 2019 Accepted: 18 December 2019

Published: 17 January 2020

Citation:

Alvarado A, Behrens $W$ and Josenhans C (2020) Protein Activity Sensing in Bacteria in Regulating

Metabolism and Motility.

Front. Microbiol. 10:3055. doi: 10.3389/fmicb.2019.03055
Bacteria have evolved complex sensing and signaling systems to react to their changing environments, most of which are present in all domains of life. Canonical bacterial sensing and signaling modules, such as membrane-bound ligand-binding receptors and kinases, are very well described. However, there are distinct sensing mechanisms in bacteria that are less studied. For instance, the sensing of internal or external cues can also be mediated by changes in protein conformation, which can either be implicated in enzymatic reactions, transport channel formation or other important cellular functions. These activities can then feed into pathways of characterized kinases, which translocate the information to the DNA or other response units. This type of bacterial sensory activity has previously been termed protein activity sensing. In this review, we highlight the recent findings about this non-canonical sensory mechanism, as well as its involvement in metabolic functions and bacterial motility. Additionally, we explore some of the specific proteins and protein-protein interactions that mediate protein activity sensing and their downstream effects. The complex sensory activities covered in this review are important for bacterial navigation and gene regulation in their dynamic environment, be it host-associated, in microbial communities or free-living.

Keywords: flux sensing, energy taxis, protein-protein interaction, iron-sulfur cluster, TCS, metabolism, flagellar motility, protein conformation

\section{CANONICAL AND NON-CANONICAL SENSORY SYSTEMS IN BACTERIA}

Bacteria face constant challenges in their changing environments. Nonetheless, bacteria can adapt and ensure their survival by employing several strategies. They can modify their cellular activities and, for instance, suppress the synthesis of certain proteins, or in turn they can produce enzymes that are required to metabolize available nutrients. Additionally, some bacteria can transition into more resistant phases (i.e., spores) in the absence of appropriate nutrition (Armitage, 1997). Another important strategy is flagella-driven motility, entailing the sensing of environmental cues and displacement of the cell to more favorable environments (Porter et al., 2011). These adaptation means are arguably analogous to the "flight or fight" responses described in higher animals (Lee and Wang, 2019; Russell and Lightman, 2019).

Vast repertoires of sensory systems that mediate these diverse and temporally distinct responses have evolved in bacteria. Well-characterized kinase-dependent systems important for sensing and signaling are two-component systems (TCSs), consisting of a sensor kinase or multi-kinase 
networks (Francis and Porter, 2019) and a corresponding response regulator (Capra and Laub, 2012; Groisman, 2016; Zschiedrich et al., 2016; Willett and Crosson, 2017). TCSs allow bacteria to sense a wide range of stimuli and induce a multitude of downstream effects, ultimately affecting gene expression (Gao and Stock, 2009; Desai and Kenney, 2017). Usually, bacteria encode a variety of different sensor kinases and TCSs, and the diversity and number of kinases can vary enormously between species, as they match the different needs within bacteria habitats (Ashby, 2004; Krell et al., 2010; Porter et al., 2011; Francis and Porter, 2019).

Canonical TCSs comprise one or several regulatory kinases and a cognate response regulator, which is phosphorylated upon sensor activation (Bourret and Silversmith, 2010; Groisman, 2016; Desai and Kenney, 2017). Canonical sensors can be membrane-bound as valid for most sensor kinases (Bourret and Silversmith, 2010; Desai and Kenney, 2017; May et al., 2019), periplasmic (Tschauner et al., 2014; Wiech et al., 2015; Matson et al., 2017; Masilamani et al., 2018), or cytoplasmic (Galperin, 2018; Osman et al., 2019). A widely studied specific example of TCS is the bacterial chemotactic sensory module, consisting of a transmembrane sensing unit, the histidine kinase CheA and the basic signaling protein CheY (Kirby, 2009; Porter et al., 2011; Parkinson et al., 2015). This system governs bacterial motility by modulating flagellar rotation and swimming direction over time, triggered by input from specialized taxis sensors (Figure 1).

We would also like to mention quorum sensing as one important subsystem of bacterial sensory activity. Quorum sensing is mediated by autoinducer (AI) molecules in concert with specific receptors, which allow bacteria to communicate in a population [summarized in two recent reviews (Papenfort and Bassler, 2016; Whiteley et al., 2017)]. The first major family of AI receptors comprises the transmembrane dimeric receptors which phosphorylate a DNA-binding response regulator, similar to canonical TCS. AI receptors of a second major family are cytoplasmic (LuxR-type family) and bear similarity to DNAbinding response regulators (Papenfort and Bassler, 2016). All quorum sensing modules seem to directly link exclusively to transcriptional regulation.

In addition to these well-characterized sensory systems and families, an increasing number of reports highlight the importance of protein activity sensing (Mascher, 2014). These non-canonical sensory processes can link to canonical sensory modules and their importance and means of action are the focus of this review.

Non-canonical sensory processes involve protein conformational changes and, frequently, specific proteinprotein interactions, which affect the downstream signaling relays and can also feed into the known kinase pathways. Furthermore, several accessory proteins of important functions in non-canonical sensing have been uncovered, including examples of proteins whose activity is sensed as an input signal of a signaling cascade. In the next paragraphs we focus primarily on recent examples which illustrate that changes in protein functionality and conformation at any given moment can be of specific importance for non-canonical sensing processes, which particularly regulate metabolism and motility, and in some cases, even act entirely independently of a TCS.

\section{REGULATORY INFLUENCE OF MEMBRANE TRANSPORT PROTEINS AND INTRACELLULAR PROTEIN ACTIVITIES IN METABOLIC HOMEOSTASIS AND ANTIBACTERIAL RESISTANCE}

The concept of co-opting accessory proteins such as transport proteins for sensory purposes in the downstream activation of TCSs has been described in several bacterial species, primarily Escherichia coli and Bacillus subtilis (see below). These coregulatory processes frequently involve the maintenance of metabolic homeostasis. Mostly, they occur at the bacterial membrane, involving transport proteins of metabolically important substrates and their regulation, thus playing a role in the co-regulation of metabolic functions by membrane-bound TCSs. Some protein activities, possibly linked to freely diffusing metabolic substrates, also contribute to cytoplasmic sensing as highlighted below.

Most classes of antibacterial compounds act on conserved central metabolic functions which directly or indirectly threaten bacterial survival and proliferation. Therefore, the maintenance of metabolic homeostasis and antimicrobial resistance mechanisms are tightly interconnected. A novel mode of protein activity sensing, termed flux sensing, involves protein conformational changes upstream of a TCS cascade (Fritz et al., 2015). In the study that first described and named this mechanism, the authors determined that the cue sensed by the bacteria is the presence of the antibiotic bacitracin. Bacitracin acts on the bacterial cell wall, and thereby indirectly impairs physiological functions of the bacterial cell (Clemens et al., 2018). The presence of bacitracin is not sensed directly by a receptor, but indirectly, via the activity of the ABC transporter BceAB of $B$. subtilis, which is located in the bacterial membrane and mediates antibiotic resistance by driving the efflux of bacitracin (Bernard et al., 2007; Dintner et al., 2014; Fritz et al., 2015). Upon activation of the transporter by its substrate, BceAB directly interacts with the histidine kinase BceS of the TCS BceS/BceR. The external and cytoplasmic levels of the antibiotic bacitracin influence the activity of the $\mathrm{ABC}$ transporter proteins $\mathrm{Bce} A \mathrm{~B}$ and as a direct consequence, regulate transcription of its own genes via the downstream signaling mediated by the TCS BceS/BceR (Figure 2A) (Dintner et al., 2011; Fritz et al., 2015). After the sensing process is initiated and upon activation by the kinase, the response regulator BceR binds DNA in order to increase the transcription of the transporter genes and other related functions (Fritz et al., 2015; Radeck et al., 2017).

Besides B. subtilis, similar complex activity sensing systems to detect the presence of antibiotics or antimicrobial peptides, exist in other Gram-positive Firmicutes (Ouyang et al., 2010; CoumesFlorens et al., 2011; Dintner et al., 2011; Muzamal et al., 2014). In fact, the impact of $\mathrm{ABC}$ transporters on TCS sensing may be 


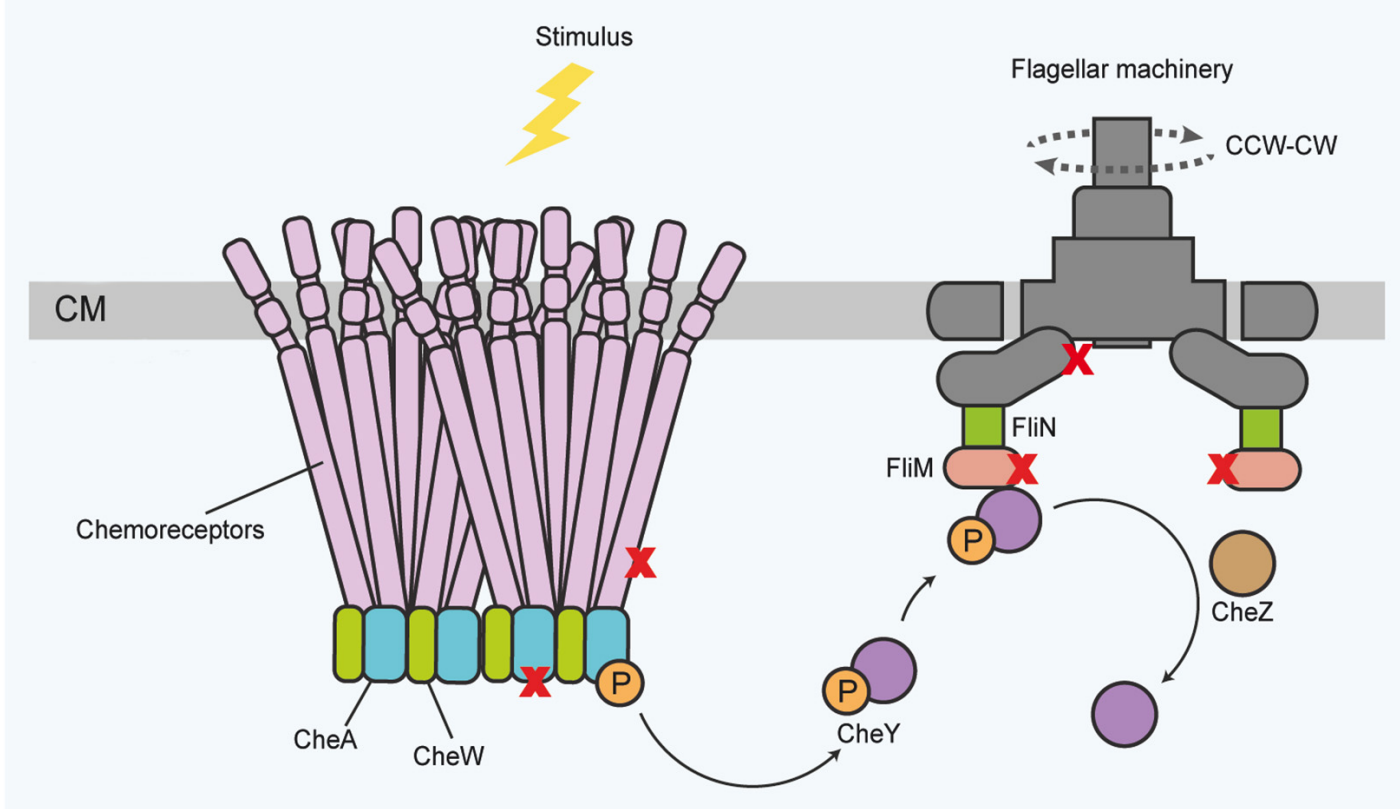

FIGURE 1 | General scheme of the canonical chemotactic sensing and signaling pathway in the bacterial membrane for governing motility functions, which are also accessible for protein activity sensing. Receptor proteins associate in large complexes of trimers of dimers, spanning the inner membrane toward the cytoplasm. In the cytoplasm, the receptors associate with the histidine kinase CheA and the adaptor protein CheW. Upon stimulus binding, CheA autophosphorylates.

Subsequently the response regulator protein CheY activates and translocates the information to the flagella motor proteins, ultimately inducing a change in the direction of flagella rotation (dotted lines) or flagellar speed. The chemotaxis components, and flagellar basal body proteins, for instance the FlhA and FliM proteins, also provide a regulatory platform for diverse activity inputs and protein-protein interactions (symbolized by X). Phosphorylated CheY can be dephosphorylated for signal termination by various proteins, for instance CheZ. CM, cytoplasmic membrane; P, phosphoryl group. CW - clockwise; CCW - counterclockwise (for the direction of flagellar rotation). The top of the panel points to the outside of the bacterial envelope.

widely distributed, in particular in the Firmicutes, where dozens of genes encoding for $\mathrm{ABC}$ transporters have been found in adjacent regions to, or even within, TCS operons (Mascher et al., 2006; Tetsch and Jung, 2009; Dintner et al., 2011; Gebhard and Mascher, 2011; Gebhard, 2012).

Another example of transport-dependent metabolic regulation in Gram-negative bacteria is the E. coli $\mathrm{ABC}$ phosphate transporter PstSCAB, which indirectly co-regulates the activity of the histidine kinase PhoR, via the linker protein PhoU (Gardner et al., 2014; Västermark and Saier, 2014), which does not itself contribute to the transporter function. Experimental evidence suggests that physical interaction between the transporter subunit PstB, along with PhoR and the auxiliary protein PhoU, ensures that phosphate limitation or phosphate repletion conditions are correctly relayed to the response regulator $\mathrm{PhoB}$ (Gardner et al., 2014; Vuppada et al., 2018). PhoR does not have a canonical periplasmic sensor domain. Instead PhoR is activated by the transporter complex PstSCAB via PhoU, and subsequently, activated PhoR relays information to the response regulator PhoB. In its phosphorylated state, PhoB activates gene expression of the pho regulon, including periplasmic alkaline phosphatase (Figure 2B) (Hsieh and Wanner, 2010). The default state of $\mathrm{PhoB}$ alone is a phosphorylated state, which can be modeled by deleting the genes encoding for the transporter proteins or phoU. Phosphate repletion in the presence of the $\mathrm{ABC}$ transporter then signals to induce phosphatase activation of the sensor kinase and dephosphorylation of PhoB (Wanner and Wilmes-Riesenberg, 1992).

Many bacteria preferentially utilize C4-carbohydrates in addition to hexoses for their metabolism. Among those, E. coli and $B$. subtilis $\mathrm{C} 4$ transporters are some of the best-characterized for auxiliary functions in signal transduction. In particular, the C4-dicarboxylate/orotate symporter DctA, which is a polarly localized non-ABC C4-carbohydrate transporter in E. coli (Scheu et al., 2014; Unden et al., 2016) and similarly in B. subtilis (Groeneveld et al., 2010; Graf et al., 2014), can form a sensory unit with a transmembrane sensor kinase. In E. coli this is the protein DcuS of the DcuS/DcuR TCS (Monzel et al., 2013). Upon DcuS activation by DctA, the response regulator is activated, leading to the upregulation of the DctA transporter (Figure 2C). Activity of the transporter itself seems not to be required for the sensing process, but DctA presence alone can provide an activity switch for the sensor kinase (Steinmetz et al., 2014). Kinase activity is dependent on the absolute protein levels of the transporter proteins, substrate availability and substrate binding to the transporter (Wörner et al., 2018), which are in turn sufficient to lead to a DctA conformational change that is possibly the signal transmitted to the kinase. 


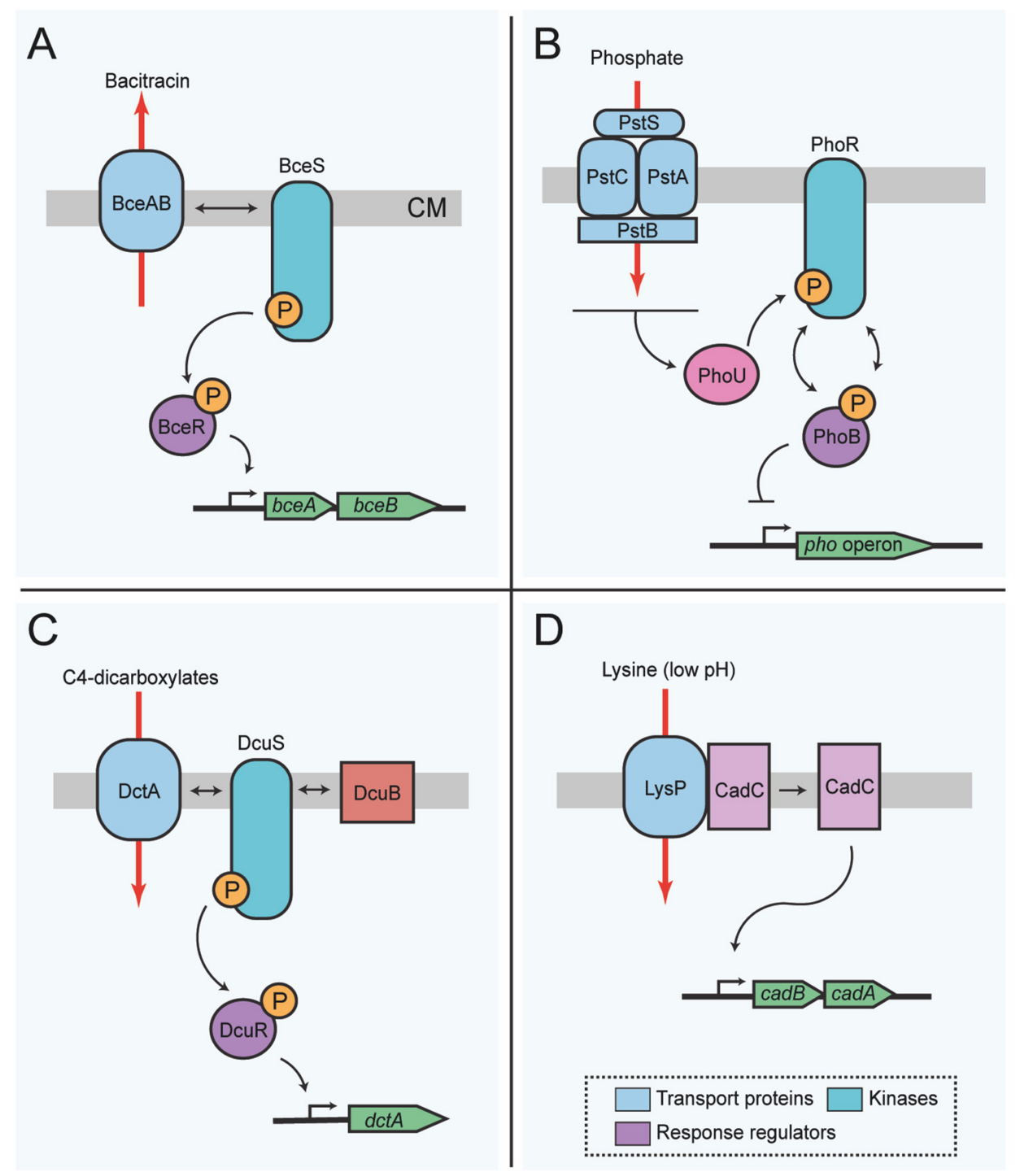

FIGURE 2 | Membrane transport functions involved in bacterial protein activity or flux sensing for metabolic homeostasis. (A) Flux-sensing by the BceRS-BceAB system described in $B$. subtilis for detoxification of bacitracin. The transporter proteins BceAB sense bacitracin, and such activity influences activation of the kinase BceS, which in turn activates the response regulator protein BceR. Active BceR recruits RNA polymerase for the transcription of genes required for the synthesis of more transporter proteins needed for detoxification of the cell. Thus, changes in the activity of the transporters is signaled from BceS to BceR, and the amount of BceR-P is proportional to the bacitracin load on the transporters. In this way, the transporter proteins are both, the sensor and the means for antibiotic resistance. (B) Sensing of external phosphate in E. coli via PhoR-PhoB. The phosphate transporter complex PstCAB perceives external phosphate levels. Phosphate binds to the transporter complex, which then transfers this information to the histidine kinase PhoR via the chaperone protein PhoU. In its default state, PhoR autophosphorylates and subsequently transfers the phosphoryl group to the response regulator protein, PhoB. However, upon phosphate binding to PstS, phosphorylation of PhoR and thus PhoB is inhibited, resulting in a concomitant decrease of the transcription of the pho regulon. (C) Sensor switch of DcuS-DcuR or DctS-DctR in E. coli and B. subtilis, respectively. Sensing of C4-dicarboxylate compounds occurs indirectly through the kinase DcuS, which complexes with transport proteins, in this example DctA and the accessory protein DcuB. Complexing of the transport protein and DcuS activates kinase activity, initiating the phoshorelay to the response regulator protein, DcuR, and ultimately inducing expression of genes for the synthesis of more transporter proteins that will eventually complex with the kinase for an increased uptake of C4-dicarboxylates. Several genes important for the synthesis of proteins required to degrade external C4-dicarboxylates are under the control of this switch; however, for simplicity only dcuB is shown. (D) Regulatory interplay between LysP and CadC. In the presence of lysine $(K)$ at low pH $(\leq 5.8)$ the lysine permease LysP interaction with the sensor protein CadC is prevented, allowing the release of CadC, which in turn induces the expression of $c a d A B$. Red arrows indicate the direction of transport. Box includes the color conventions of shared elements between systems. CM, cytoplasmic membrane; P, phosphoryl group. The top of each panel points to the outer face of the bacterial envelope.

A similar mechanism with a close association of signal transfer and signal conversion by a transporter has also been described for E. coli DcuB, an aerobically active fumarate/succinate $\mathrm{C} 4$ antiporter, which also directly interacts with and activates the histidine kinase DcuS (Pappalardo et al., 2003; Kneuper et al., 2005; Kleefeld et al., 2009; Witan et al., 2012; Strecker et al., 2018; 
Wörner et al., 2018). Under aerobic conditions, DcuB can replace anaerobically active DctA as co-sensor for the TCS, such that under both divergent conditions, appropriate target genes can be activated by the response regulator. Interestingly, when both $d c t A$ and $d c u B$ are absent, the kinase DcuS is completely deregulated and in a constitutively active state, even if no $\mathrm{C} 4$ transport substrates are present (Kleefeld et al., 2009).

In B. subtilis, the transporter DctA, an orthologous C4 transporter protein as the one reported in E. coli, activates the B. subtilis DctS/DctR TCS. In this case, a second accessory protein, DctB, which is a membrane co-receptor for C4carbohydrates, has to be present as well to initiate the sensing process, probably acting as a tripartite sensory unit together with DctS and DctA, each binding at different domains of the sensory kinase (Graf et al., 2014).

Such co-regulatory mechanisms may not only be widespread for carbohydrate transporters, but also for amino acid transport proteins such as CadC, which is part of an E. coli onecomponent system that receives information on lysine availability from LysP, a lysine-specific membrane-associated amino acid permease (Figure 2D) (Tetsch and Jung, 2009; Haneburger et al., 2011; Rauschmeier et al., 2014; Brameyer et al., 2019). When lysine is available and the cell is under stress due to low $\mathrm{pH}$, the sensor protein CadC activates the expression of the cadBA genes. CadA is a lysine decarboxylase, while $\mathrm{CadB}$ acts as a lysine/cadaverine antiporter (Fritz et al., 2009). Thus, lysine is converted to cadaverine via CadAmediated decarboxylation reaction, which ultimately raises the intracellular $\mathrm{pH}$. Meanwhile, $\mathrm{CadB}$ transports lysine into the cell and cadaverine out. The presence of lysine is transduced to CadC via LysP (Tetsch et al., 2008; Rauschmeier et al., 2014). LysP inhibits the dimerization of CadC under non-inducing conditions, but when the external $\mathrm{pH}$ drops, CadC undergoes structural modifications that permit its binding and consequent activation of the cadBA operon (Haneburger et al., 2011, 2012; Lindner and White, 2014; Buchner et al., 2015).

One example of protein activity sensing concerning the membrane but not immediately involved in transport evolved with the nitrate sensor NtrB in E. coli (Buelow and Raivio, 2010). The NtrB activating system is indirectly associated with ammonium transport and has recently been termed a "Level and Activity Proportional Integral" (LA-PI) sensorcontroller, optimized for performance under stepwise changing environmental conditions (Mairet, 2018). Specifically, the LAPI pattern of feedback control refers to a specific feedback system which acts by both, transcriptional and post-translational, feedback regulation toward the same regulatory protein (any given biomolecular control protein), which thereby acts as a proportional integral (PI) controller (Mairet, 2018). Modeling of the feedback response of active sensory proteins to their substrates demonstrated that indeed feedback control plays an important role in the response by various sensors (Mairet, 2018). Chemotactic responses have been modeled as direct zero integral feedback control (Dufour et al., 2014).

The intracellular kinase $\mathrm{NtrB}$ is connected physically to the regulatory PII protein $\mathrm{GlnB}$ and controls, among others, the biogenesis and activity of the AmtB ammonium importer
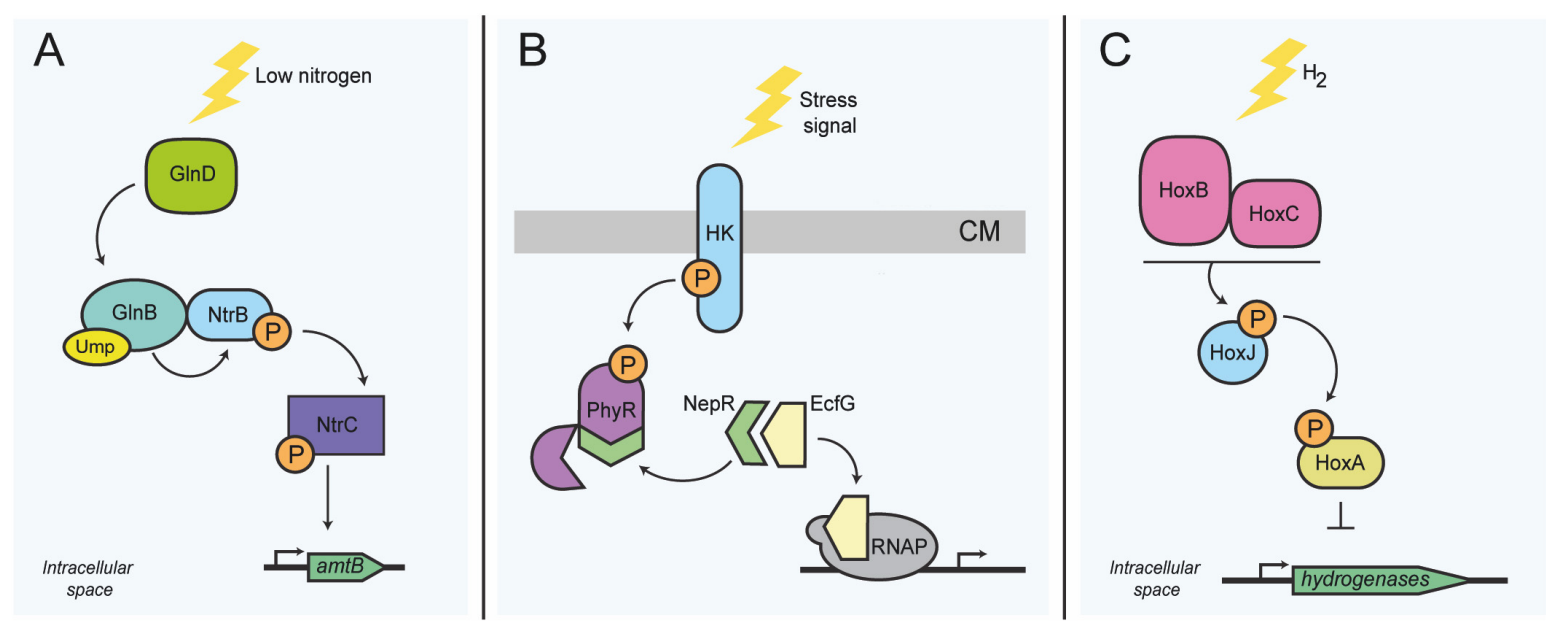

FIGURE 3 | Activity sensing in intracellular bacterial functions related to metabolism. (A) Nitrogen stress response in E. coli. At low nitrogen levels, GlnD uridylates GlnB. GlnB-UMP subsequently activates the TCS NtrB/NtrC. The intracellular kinase NtrB autophosphorylates, and in turn phosphorylates the DNA-binding transcriptional regulator NtrC; activation of NtrC is needed for the transcription of several genes, including amtB. (B) Transcription control switch of the general stress response in alphaproteobacteria. Stress sensing activates autophosphorylation of the histidine kinase, which in turn phosphorylates the regulator protein PhyR. Phosphorylation of PhyR induces its conformational change, allowing the sequestration of the anti-sigma factor NepR, consecutively releasing the transcriptional regulator sigma-EcfG, which permits the transcription of general stress response genes. (C) $\mathrm{H}_{2}$ sensing in $R$. eutropha. Expression of genes required for the synthesis of hydrogenases is controlled via sensing of molecular hydrogen by the intracellular $\mathrm{Ni}^{2+} \mathrm{Fe}^{2+}$ hydrogenases HoxB and HoxC, which then interact presumably with the histidine kinase HoxJ. HoxJ, when activated by HoxBC, prevents HoxA-mediated transcription of several hydrogenase genes (horizontal line). HK, histidine kinase; RNAP, RNA polymerase; CM, cytoplasmic membrane; P, phosphoryl group; UMP, Uridine monophosphate group. The top of panel B points to the outer face of the bacterial envelope. 
(Huergo et al., 2013; Mairet, 2018). The bifunctional glutaminesensing protein $\mathrm{G} \ln \mathrm{D}$ uridylates $\mathrm{G} \ln B$ and thereby regulates $\mathrm{G} \ln B$ conformation and direct GlnB-NtrB binding (Zhang et al., 2010). During states of high intracellular ammonium concentration, GlnB in complex with NtrB represses transporter activity and transcriptional activation of downstream genes via the response regulator NtrC (Figure 3A) (Zimmer et al., 2000; Huergo et al., 2013). In order to initiate the transcription of genes required for nitrogen assimilation, the phosphorylated form of NtrC binds DNA. Ultimately this interaction facilitates access of the RNA polymerase subunits to the promoter region (Hervas et al., 2009). Similar signaling pathways also exist in other bacteria, such as Sinorhizobium meliloti, Rhodospirillum rubrum, and Azospirillum brasilense (Zhang et al., 2010; Inaba et al., 2015; Hauf et al., 2016).

More complex activity sensing can also involve anti-sigma factors, which generally require conformational change to associate or disassociate with their cognate binding proteins. One common sensory module involves the interaction between the response regulator PhyR and the anti-sigma factor NepR of Caulobacter crescentus. Kinase activation upon stress sensing permits phosphorylation of PhyR. Activation of PhyR induces its conformational change that permits binding of the anti-sigma factor NepR; this in turn allows the release of the sigma factor EcfG and the consequent transcription of general stress response genes (Figure 3B) (Herrou et al., 2010; Fiebig et al., 2015). This system is widespread amongst alphaproteobacteria and controls the general stress response (Fiebig et al., 2015).

In order to illustrate that protein activity sensing can also be crucial for exclusively intracellular sensory capacities, we highlight the hydrogenase HoxBC of Ralstonia eutropha. The HoxBC complex converts hydrogen into protons and electrons and acts as a cytoplasmic hydrogen sensor in connection with the histidine kinase HoxJ and the regulator protein HoxA. HoxA acts as the main DNA-binding transcriptional activator of hydrogenase genes found within several operons present in R. eutropha (Figure 3C) (Buhrke et al., 2004; Jugder et al., 2015). The exact sensory mechanism is still under investigation, but likely involves enzyme activity changes under conditions of oxidative stress. Oxidation can cause structural alterations to the iron-sulfur clusters present in HoxBC (Löscher et al., 2010), which is likely to lead to protein conformational changes or unfolding, which might then indirectly mediate hydrogen sensing. The differential interaction of the HoxBC complex with the kinase HoxJ is supposed to play a role in this sensing mechanism (Buhrke et al., 2004). This alternative display of two divergent functions is not unique of these proteins, as it has been shown for other proteins such as the cytoplasmic enzyme aconitase in E. coli, Helicobacter pylori and other organisms (Kiley and Beinert, 2003), which will be discussed in detail further ahead.

Altogether, these examples not only point at the major role of non-canonical sensory proteins in the activation of one and TCSs, they also highlight the relevance of activity sensing in the regulatory responses to diverse extra- and intracellular stimuli. Transport proteins as well as intracellular sensors not only mediate the activation of response regulator units, their activity also coordinates transcriptional regulation of downstream components that ultimately control the cellular response to antibiotics or metabolic maintenance. We speculate that the possibility to elicit a response via protein activity sensing could attend to the need for subtle but rapid changes in the face of continuous environmental challenges. This could have led to an evolutionary selection of protein activity sensing, which seems to convey a larger flexibility to the regulatory modules.

\section{PROTEIN-PROTEIN INTERACTION SENSING IN FLAGELLAR ASSEMBLY REGULATION}

The expression of flagellar genes in various bacteria is organized in a complex regulatory hierarchy. Although the number and organization of flagellar genes in the genome varies between bacterial genera, some analogies in hierarchical structure and feedback mechanisms are maintained (Chevance and Hughes, 2017). This hierarchical structure can include the $(\sigma 80)$ housekeeping sigma factor as well as the subordinate regulators $\sigma 54$ and $\sigma 28$ for middle and late flagellar genes, and further regulators, such as the anti- $\sigma 28$ factor FlgM. FlgM provides the last assembly feedback step, which releases the late sigma factor FliA to produce late flagellar structural proteins such as the flagellins if the flagellar basal body and hook are completed (Chevance and Hughes, 2017). For instance, in the Epsilonproteobacterium $H$. pylori, which has a three-tiered regulatory hierarchy of flagellar expression and assembly, including three sigma factors and a FlgM feedback loop (Niehus et al., 2004), researchers have found that several flagellar structural proteins are involved in flagellar regulation. These proteins include the basal body component FlhA, an essential part of the basal body and the assembly platform (Schmitz et al., 1997; Rust et al., 2009; Minamino et al., 2016a,b; Terahara et al., 2018) as well as FlhF, considered a signal recognition particle (SRP)like protein important for flagellar localization (Bange et al., 2007; Kazmierczak and Hendrixson, 2013; Kondo et al., 2017); additionally the TCSs FlgS-FlgR and ArsS-ArsR are involved (Pflock et al., 2006; Loh et al., 2010; Marcus et al., 2016; Xiong et al., 2019).

These components, together with their known transcription factors, contribute to an expression cascade, which allows the coordinated buildup of the complex flagellar structure (Figure 1), involving early (class 1), intermediate (class 2 and 3), and late (class 3) flagellar genes (Niehus et al., 2004; Lertsethtakarn et al., 2011). It is well established in various species that a deficiency of $f$ th $A$ by directed mutagenesis leads to the downregulation of numerous middle and late flagellar transcripts (Minamino and Macnab, 1999; Niehus et al., 2004; Tsang et al., 2015; Barker et al., 2016).

In Enterobacteriaceae as well as in Epsilon-proteobacteria, late FlhA-dependent regulatory events involve the anti-sigma factor FlgM, whereby the disruption of the flagellar secretion process directly impacts on late gene regulation (Josenhans et al., 2002; Rust et al., 2009; Chevance and Hughes, 2017). However, it is not known how flagellar structural proteins such as FlhA can contribute to flagellar type III secretion-independent regulation 
events of earlier expressed genes (class 2 flagellar genes). FlhA is known to harbor a critical patch of charged amino acid residues in a cytoplasmic loop which can influence its conformation (Erhardt et al., 2017). In H. pylori, the expression of intermediate (class 2 and class 3) flagellar genes is regulated by the cytoplasmic TCS FlgS-FlgR and its impact on $\sigma 54$-dependent transcription (Niehus et al., 2004). The signal sensed by the cytoplasmic sensor histidine kinase FlgS and which initiates middle (class 2) flagellar gene expression is currently unknown. Recent studies indicated that FlhA of $H$. pylori directly interacts with cytoplasmic FlgS (Tsang et al., 2015). This protein-protein interaction might be of particular importance to the cytoplasmic sensory activity of FlgS and its downstream regulation via the response regulator FlgR, and may subsequently serve to maintain a functional flagellar assembly (Tsang et al., 2015). The same group has also demonstrated that the N-terminal domain of FlhA was sufficient for the $\sigma 54$-dependent expression of the middle flagellar genes (Tsang et al., 2013), while it was not sufficient to mediate flagellar assembly and secretion. Since the direct interaction between FlgS and FlhA did not cause downstream signaling via FlgR phosphorylation in a reconstituted system in vitro, this proteinprotein interaction may not be functional alone, but may be just one component of a larger, functional, protein complex involving other regulatory proteins (Tsang et al., 2015). The response regulator FlgR can act as a transcriptional activator without its cognate sensor kinase and is constitutively active in the absence of phosphorylation. Phosphorylation might therefore serve to modulate its activity or alter its range of transcriptional targets. Interestingly, the FlgS-FlgR pair do not only regulate motility genes but also metabolic functions (Niehus et al., 2004), which may provide a functional coupling between metabolic adaptation and motility. The mechanisms of function of FlgS/FlgR-like regulators in other bacterial species (Dasgupta et al., 2003; Jacobi et al., 2004; Boll and Hendrixson, 2013) remain yet to be clarified.

In summary, these novel interaction-dependent mechanisms of flagellar sensing indicate that flagellar hierarchy is not only governed by transcriptional regulators involving transmembrane TCS and transport-dependent anti-sigma factors, but also by an intracellular, TCS-dependent sensing mechanism which is not acting alone, but requires auxiliary proteins. These can be structural proteins such as FlhA, but may also involve larger protein complexes. The mechanisms of non-canonical sensing and protein interactions in flagellar regulation in various species need to be investigated in more detail.

\section{MODULATION OF MOTILITY AND TAXIS BY CO-REGULATORY PROTEIN-PROTEIN INTERACTIONS AND CONFORMATIONAL CHANGES}

Chemotaxis sensors can be transmembrane or soluble dimeric sensors, which form arrays of trimers of dimers (Briegel et al., 2014; Mauriello et al., 2018) and sense different environmental and internal cues. By interacting with the chemotaxis TCS formed by CheA and CheY, they feed sensory information to the basal body of the flagellar organelle (Porter et al., 2011; Parkinson et al., 2015). Several studies in different bacterial species provided preliminary data that taxis systems and flagella can sense protein activities or changes in protein-protein interactions, reviewed in Anderson et al. (2010), and also further outlined below. This may be of particular importance for motility functions, since they are required to provide a rapid response to changing environmental conditions, by modifications of either flagellar rotational speed or the direction of rotation (Baron et al., 2017; Koganitsky et al., 2019; Nieto et al., 2019), which are both important for the directionality of the biased random walk. Flagellar speed is set at the rotary motor and its interacting flagellar basal body proteins (Nesper et al., 2017). The direction of flagella rotation is influenced by receptor proteins (methyl-accepting proteins [MCP]), which transmit signals to the flagellar base proteins (FliM) via the kinase CheA (Muok et al., 2019a) and the taxis response regulator protein CheY (Figure 1) (Baker et al., 2006; Di Paolo et al., 2016; Nishikino et al., 2018; Mukherjee et al., 2019; Ward et al., 2019). Therefore, signals feeding into flagellar rotational speed and direction intersect at the flagellar basal body. Several independent studies discussed below reported that proteins of the electron transport chain directly affect motility and taxis. Earlier it was demonstrated that a direct interaction of the bacterial fumarate reductase with the flagellar switch apparatus in E. coli, which constitutes a regulatory factor for flagellar rotation, depends on fumarate reductase enzymatic activity (Barak et al., 1996; Cohen-Ben-Lulu et al., 2008). Later, it was also reported that both the $\mathrm{F}_{0} \mathrm{~F}_{1}$ ATP synthase and NADHubiquinone oxidoreductase interact with flagellar basal body proteins in E. coli (Zarbiv et al., 2012). Furthermore, microscopy studies demonstrated that respiratory chain components of $E$. coli and $B$. subtilis arrange in mobile or dynamic aggregations, which are distributed over the whole cell membrane without a preference for the poles or permanent co-localization with the chemotaxis clusters at this site (Johnson et al., 2004; Lenn et al., 2008; Llorente-Garcia et al., 2014). It can be hypothesized that respiratory chain proteins co-localize with chemotaxis clusters or flagella only temporarily and in a dynamic manner, which might then be instrumental for regulatory processes impacting on speed or direction of flagellar rotation.

In fact, besides modes of bacterial chemotaxis sensing which is based on direct binding of small molecule ligands to periplasmic receptor domains of the MCPs, an alternative sensing mechanism, termed energy taxis, has been observed to be widespread in diverse bacterial and archaeal species (Glagolev, 1980; Taylor et al., 1999; Schweinitzer et al., 2008; Alexandre, 2010). Energy taxis can be defined as a metabolism-dependent sensing by intracellular sensors, which includes the integration of multiple cues and signals derived from environmental conditions related to the intra-bacterial energy state and possibly involving protein activity (Taylor et al., 1999; Schweinitzer and Josenhans, 2010). However, distinct mechanisms of energy sensing have only been reported so far for a handful of designated receptor proteins, which are not canonical transmembrane receptors, but are placed in the cytoplasm (Packer and Armitage, 2000a,b; Muok et al., 2019b). One family of intracellular soluble receptors, which respond to oxidative conditions and oxygen and were previously 
suspected to sense energy indirectly, are in fact activated by an auxiliary sensory subunit protein, ODP, which can directly bind iron and oxygen (Muok et al., 2019b). ODP directly interacts conformation-dependently with its cognate receptors. However, in the absence of a dedicated auxiliary sensory unit protein, other mechanisms related to protein activity sensing have been proposed for several receptor proteins as summarized below.

The chemotaxis model organism E. coli was shown to employ two energy sensors, Aer and Tsr (Rebbapragada et al., 1997; Edwards et al., 2006). Aer, initially characterized as an aerotaxis or oxygen taxis sensor carrying a PAS domain, was demonstrated to respond to the intra-bacterial redox potential associated with the electron transport chain. In-depth studies into the E. coli Aer sensing mechanism suggest that a close, likely direct, physical association of Aer and the respiratory enzyme NADH dehydrogenase exists (Edwards et al., 2006). Suggestions on the molecular mechanism have taken into consideration a sensing of electrons from the electron transport chain to Aer via its noncovalently bound FAD cofactor (Rebbapragada et al., 1997; Garcia et al., 2016; Samanta et al., 2016), and a direct interaction of Aer with an electron transport chain enzyme (Edwards et al., 2006). Such an interaction could deliver information on the intracellular redox potential to Aer. Currently, there is no evidence for direct ligand binding other than FAD by Aer or direct protein-protein interactions. Further studies are needed to address the hypothesis of Aer activity sensing.

More evidence for a strong connection between membrane processes, nutrient acquisition, metabolism, and motility regulation comes from carbohydrate uptake systems at the bacterial membrane. Carbohydrate uptake by the phosphotransferase system (PTS) is a central metabolic function for carbohydrate uptake in many bacteria that also has diverse roles in regulation, including motility and taxis (Deutscher, 2008; Joyet et al., 2013; Deutscher et al., 2014).

The PTS is one of the early examples of protein activity sensing by the activity of a membrane transport system, which is metabolically active and at the same time relays information to transcriptional regulators. In many Proteobacteria, also a truncated, secondary PTS exists (PTSNtr), which only acts in regulation. In E. coli, PTSNtr interacts with the potassium transporter TrkA and the sensor kinase $\mathrm{KdpD}$, influencing the activity and expression of these and other target proteins (Luttmann et al., 2015). In R. eutropha, EIIA(Ntr) interacts with the bifunctional ppGpp synthase/hydrolase SpoT1, a key enzyme and regulator of the stringent response (Karstens et al., 2014). The EIIA(Ntr) enzyme of this truncated system was thereby able to regulate different metabolic pathways and to transfer nutritional information to the regulatory systems of the bacteria. Other PTS components such as the small heat-stable phospho-carrier protein HPr are also able to bind transcriptional regulators, such as the stationary-phase anti-sigma factor Rsd, which regulates SigmaD activity in E. coli, but the downstream outcome of this interaction is less clear (Neira et al., 2018).

The PTS system, among other regulatory functions, also delivers signals to the chemotaxis cascade (Neumann et al., 2012) which then regulates chemotaxis. This was underpinned in a more recent study, when direct protein-protein interactions of
PTS components with the taxis TCS were studied and confirmed by positive FRET signals between a CheZ and CheY FRET pair in E. coli (Somavanshi et al., 2016). In these assays, it was demonstrated that the integrated output of the complete PTS network is transmitted linearly to the chemotaxis pathway, in stark contrast to the amplification of conventional chemotactic stimuli (Somavanshi et al., 2016).

Earlier, RecA, the major bacterial recombinase which mediates homologous recombination of DNA, has been shown to play a role in chemotactic and swarming phenotypes and polar localization of a chemoreceptor in Salmonella enterica serovar Typhimurium (Mayola et al., 2014). RecA was also found to interact directly with the taxis adaptor protein CheW. In a followup study, the same group demonstrated that the inhibition of bacterial surface swarming was due to the net increase of RecA over the taxis sensor kinase CheA in stressed cultures which mounted an SOS response (Irazoki et al., 2016). However, only the presence and increase in protein amounts of RecA, and not necessarily its activation, were sufficient to stop swarming ability. This phenotype seems to be directly related to the extent of polar localization of the chemotaxis machinery, but the exact mechanism remains to be clarified (Irazoki et al., 2016).

In another model bacterium with four taxis sensors, $H$. pylori, the activity of the electron transport chain as a marker of metabolic sufficiency has been proposed to be crucial for energytactic behavior by the non-transmembrane taxis receptor TlpD, although it is not clear whether protein activity sensing might directly contribute to these functions (Schweinitzer et al., 2008; Collins et al., 2016). The soluble intracytoplasmic taxis sensor TlpD mediates energy taxis (Schweinitzer et al., 2008), which has been demonstrated as repellent taxis away from conditions of reduced respiratory chain activity, such as that induced by specific inhibitors (Schweinitzer et al., 2008) or redox stress (Collins et al., 2016). Several of the respiratory chain proteins in all bacteria contain iron-sulfur clusters which are redoxsensitive. In $H$. pylori, some of those are connected to sensing performed by TlpD (Behrens et al., 2016). The authors identified several novel intracellular protein interaction partners of TlpD by mass spectrometry, including the iron-sulfur cluster-containing enzyme aconitase (AcnB) (Austin et al., 2015; Behrens et al., 2016). Besides the metabolic enzyme $A c n B$ and the chemotaxis histidine kinase CheAY2, catalase KatA was detected as direct physical interactor of TlpD. Additionally, AcnB and KatA were shown to play a role in the subcellular localization of TlpD (Behrens et al., 2016). The subcellular localization of TlpD can vary between the formation of polar foci, and a cytoplasmic diffuse localized portion, dependent on external nutrient availability and stress conditions (Behrens et al., 2016). However, despite a clear involvement of the respiratory chain in this energy sensing process (Schweinitzer et al., 2008), no evidence has been obtained yet that electron transport chain components interact directly with the chemotaxis or flagella machinery in $H$. pylori.

Conversely, TlpD had an effect on transcriptional regulation, impacting the expression of numerous genes involved in redox homeostasis and metabolism (Behrens et al., 2016). Therefore, it has been hypothesized that TlpD could serve as a linker between 
the taxis response and metabolic regulatory responses, possibly via the bifunctional regulatory protein AcnB (Austin et al., 2015; Behrens et al., 2016) (see next chapter for AcnB regulatory function). This direct link might be required to cope with energy limitation conditions, thus providing an immediate mechanism to improve the intracellular state of the cell. Furthermore, TlpD integrates responses of the other $H$. pylori taxis sensors (TlpA, $\mathrm{TlpB}$, and TlpC), because it can initiate a dual response not only on the level of motility in the short-term but also by influencing metabolic gene regulation in the medium temporal range.

Taken together, emerging evidence shows the presence of a functional coupling, either by direct interaction or regulatory effects of metabolic enzymes, between electron transport chain components and other transport systems to regulators of metabolic functions, motility and flagella, including the bacterial taxis systems. We argue that this link is crucial in order to connect the energy-consuming functions of the flagellar apparatus to the sum of metabolic activities providing the necessary energy. This link might have been selected during evolution to provide useful feedback responses from metabolism to motility and taxis and vice-versa, in order to adjust motility functions, such as flagellar rotation, number of flagella, or the functionality and amount of chemotaxis receptors to the levels in energy and metabolic activity. These connections underline how important it is for bacteria to efficiently transmit and integrate information on the intracellular energy and nutritional levels into their sensory circuitry. Although the function and evolutionary aspects of the activity sensing processes related to motility are not entirely clear, they definitely highlight the importance to better understand the mechanisms behind the sensing of the intracellular energy state, which may depend on protein activities and proteinprotein interactions.

\section{IMPORTANT MOONLIGHTING PROTEINS IN MOTILITY AND METABOLISM}

A discussion about protein activity sensing in metabolism and motility also requires the mention of the term moonlighting proteins. The term was coined about two decades ago (Jeffery, 1999), to describe proteins which carry out several (at least two) physiological functions, which frequently include protein or DNA binding at the same time as they undergo conformational change, which leads to the loss of another function or activity such as a catalytic one (Jeffery, 2019). Some of these proteins can perform their two roles in parallel or shift gradually between two functions, depending on the environmental and intracellular conditions. Up to now, more than 300 moonlighting proteins have been described in different classes of protein functions, for instance, metabolic enzymes, transcription factors and receptors, comprising many eukaryotic and prokaryotic species (Jeffery, 2014). Since their enzyme activity is closely connected to the surrounding conditions, they represent another layer in the regulatory network within a cell. Among the many moonlighting enzymes and proteins with dual, alternating functions, there are numerous examples which moonlight as important regulators or co-regulators of metabolism in bacteria, but relatively few for motility functions. Indeed, we have recognized some novel moonlighting proteins which have a second function as sensors already in the above paragraphs, and we will highlight here a few others which are specifically involved in motility and metabolism.

One prominent and well-characterized example is the citrate cycle enzyme aconitase (AcnB). AcnB has been described as a moonlighting protein with dual functions in E. coli, H. pylori and other organisms including Homo sapiens (Tang et al., 2005; Austin and Maier, 2013; Jeffery, 2014). Several studies concordantly show that aconitases of various organisms can perform a biphasic switch between a metabolically active and a regulatory function by protein conformational changes (Kiley and Beinert, 2003; Tang et al., 2005; Austin and Maier, 2013; Lushchak et al., 2014; Austin et al., 2015). Under oxidative stress or iron depletion, which destroys the iron-sulfur clusters essential for its enzymatic activity, aconitase partially unfolds and can itself bind to particular mRNA sequences, resulting in either an increased or decreased mRNA stability and altered translation of the respective proteins (Lushchak et al., 2014). This ability to couple protein activity with posttranscriptional regulation constitutes a second mode of bacterial sensing-signaling of protein activities with conformational change. In $H$. pylori, aconitase-dependent regulation impacts on both metabolic and motility functions (Austin et al., 2015). By RNA mobility shift and proteomics, the authors of the latter study demonstrated that aconitase influences the expression of the intracellular flagellar regulator $f \operatorname{lgR} / \mathrm{FlgR}$, the FlgRS-RpoN-FlgE cascade, and the metabolic proteins urease and hydrogenase. Aconitase also exerts an influence on flagellin gene expression and motility in S. enterica serovar Typhimurium (Tang et al., 2004). Concordantly, an aconitase mutant showed considerably lower protein levels of the main flagellin FliC. The authors found that this is indirectly mediated, most likely by a stabilizing effect of aconitase on mRNA of the protease gene ftsH (Tang et al., 2004).

In Listeria monocytogenes, which is only motile at lower temperatures due to its biphasic switch between environmental and host-associated lifestyle, GmaR, a bifunctional Glc-Nac transferase, moonlights in motility regulation under conditions of low temperature, when DegU-dependent transcription of its own gene is initiated (Shen et al., 2006). Upon production, GmaR binds the constitutively expressed motility repressor MogR and relieves MogR repressor function on motility genes. At the same time, GmaR functionally acts as a glycosylation enzyme for the main flagellin FlaA, which it helps to produce. Upon a temperature shift to $37^{\circ} \mathrm{C}, \mathrm{GmaR}$ undergoes a conformational change which abolishes its MogR binding and anti-repressor function (Kamp and Higgins, 2011).

Numerous examples of mostly metabolic proteins moonlighting as transcriptional or posttranscriptional coregulators have been reported (Commichau and Stülke, 2015; Monahan and Harry, 2016). In the following, we would like to highlight just a few of those which are so far known exclusively for broadly regulating core metabolic functions. One important moonlighting protein involved in metabolic regulation is PutA of Salmonella, which, on one hand, functions as a proline dehydrogenase, converting proline to glutamate for metabolic purposes, and on the other, as a direct transcriptional repressor 
of the put operon involved in amino acid conversion (Liu et al., 2017). Similarly, BirA of E. coli harbors enzymatic activity as a biotin synthetase and moonlights as a transcriptional repressor of the bio operon (Barker and Campbell, 1981). In the B. subtilis glutamine pathway, the enzyme glutamine synthetase, termed an activity sensor for nitrogen availability (Wray et al., 2001; Mirouze et al., 2015), binds to the transcription factor TnrA, a global regulator of transcription, and prevents TnrA from binding to DNA (Wray et al., 2001), which influences multiple metabolic pathways (Mirouze et al., 2015; Randazzo et al., 2017). Also in the glutamate pathway, glutamate dehydrogenase interacts directly with GltC, a LysR-type transcription factor, to influence its transcription-enhancing activity (Gunka et al., 2010; Stannek et al., 2015). Additional examples of mostly metabolic proteins moonlighting as transcriptional or posttranscriptional co-regulators have been reported (Commichau and Stülke, 2015; Monahan and Harry, 2016).

In summary, there are many examples which link the maintenance of physiological and metabolic functions to activity sensing mechanisms. Metabolic functions and the control of influx of metabolic substrates are an important source of protein co-factors and sensory proteins necessary for the regulation of intracellular metabolism and other important functions such as motility.

\section{INTEGRATION OF BACTERIAL PROTEIN ACTIVITY SENSING INTO REGULATORY CIRCUITRY AND ENVIRONMENTAL ADAPTATION}

While bacteria have evolved highly coordinated regulatory systems, it is unclear why protein activity sensing is required or how it is integrated into the regulatory circuitry. Signal integration can work by varying protein expression levels, their activity, conformation and the subcellular localization of the sensory cofactors or the activity-sensing components themselves. Several examples explained above highlight that protein activity sensing in combination with expression levels and feedback mechanisms helps to integrate information on metabolic activities, environmental conditions such as temperature, nutrient transport, oxygen and iron stress, in a direct and fast manner.

Alternative models of signal integration into circuits, which are emerging from recent studies in different bacterial species, include a dynamic protein localization with subcellular rearrangements upon different signals, not only for transmembrane receptors but also for other bacterial proteins (Borrok et al., 2008; Wu et al., 2011; Alberge et al., 2015; Hiremath et al., 2015). In particular, metabolic features in general seem to have a high potential to influence protein localization. For example, in Vibrio cholerae, one set of transmembrane chemotaxis components localized either at the pole or diffuse in the cell depending on the presence and absence of oxygen which can be used as electron acceptor (Hiremath et al., 2015). Recently, in E. coli the nitrate reductase, one component of the electron transport chain which is necessary for anaerobic respiration, was also reported to localize dynamically upon switches between aerobic or anaerobic conditions (Alberge et al., 2015). Only few data are available on soluble cytoplasmic receptors which might regulate motility. One important example is the soluble taxis receptor AerC from A. brasilense, which dynamically localizes to the cell poles depending on the levels of oxygen, which is an important factor to guide the bacteria and contribute to their metabolic activity (Xie et al., 2010).

In order for bacteria to thrive in different habitats, efficiency in energy sensing and the integration of multiple signals are essential. For pathogenic and non-pathogenic bacteria, the regulatory properties and survival strategies have been evolved to cope with complex and variable environments. While in the early days of pathogen research, researchers focused on the effect of virulence factors in host damage, recently the combination of bacterial traits is viewed more in the context of optimizing the metabolic situation inside the host niche to the benefit of specific bacteria (Winter et al., 2010; Rivera-Chavez et al., 2013, 2016; Eisenreich et al., 2015). This requires multiple modes of signal integration and regulatory crosstalk, which might involve the direct and indirect sensing of environment- or host-derived compounds and metabolites (Sule et al., 2017; Lopes and Sourjik, 2018) as well as metabolic protein activities which feed into sensing. In addition to taxis receptors which perform regulatory functions, some organisms might also dedicate entire chemotaxis systems to perform exclusively regulatory functions benefiting specific lifestyles such as bacterial biofilms or host-associated biology (García-Fontana et al., 2013; Xu et al., 2017). For instance, in the enteropathogen $V$. cholerae, there are three different operons (cluster I, II, and II) encoding for chemotactic-related genes (Ringgaard et al., 2018). In V. cholerae, genes from cluster II encode proteins responsible for chemotactic behavior in most environmental conditions. Meanwhile, cytoplasmic receptors associated with proteins encoded by genes from cluster I are specifically induced under low oxygen conditions (Hiremath et al., 2015), leading to the suggestion that these particular receptors and its associated proteins are responsible for chemotactic activity and survival in the host intestine (Hiremath et al., 2015; Briegel et al., 2016). Moreover, it has been observed that cluster III proteins are observable in microscopy studies during stationary phase only (Ringgaard et al., 2015). Other studies have shown that several chemosensory systems have outputs other than mediating a chemotactic response (Kirby, 2009; Wuichet and Zhulin, 2010), and instead regulate alternative functions, such as type IV-pilimediated motility or the modulation of intracellular levels of secondary messengers (Hickman et al., 2005; Zusman et al., 2007; Wuichet and Zhulin, 2010).

\section{CONCLUSION AND FUTURE DIRECTIONS}

Numerous examples now illustrate the role of non-regulator proteins with important primary functions in membrane transport or metabolism as cofactors in central regulatory 
processes, for example those governing bacterial metabolism, taxis and motility. However, some of the important mechanisms of their sensory and regulatory functionality, in the context of their structure and possible modifications, remain unknown. More examples of complex sensory perception and signal integration by activity sensing and protein-protein interactions are to be discovered in all bacterial taxons. Further research is required to decipher the mechanisms behind temporal and spatial protein activities and localization dynamics, and how those feed into their activities as sensors, cofactors or transmitters of signals. The value of such functions can also be appreciated by mathematically modeling their influence on the activity kinetics of sensory systems and their output. A greater understanding of these processes will be beneficial to the study of bacterial sensing, inter-species communication and their proliferative capacities in the context of hosts and other relevant environments.

\section{REFERENCES}

Alberge, F., Espinosa, L., Seduk, F., Sylvi, L., Toci, R., Walburger, A., et al. (2015). Dynamic subcellular localization of a respiratory complex controls bacterial respiration. eLife 4:e05357. doi: 10.7554/eLife.05357

Alexandre, G. (2010). Coupling metabolism and chemotaxis-dependent behaviours by energy taxis receptors. Microbiology 156, 2283-2293. doi: 10.1099/mic.0. 039214-0

Anderson, J. K., Smith, T. G., and Hoover, T. R. (2010). Sense and sensibility: flagellum-mediated gene regulation. Trends Microbiol. 18, 30-37. doi: 10.1016/ j.tim.2009.11.001

Armitage, J. P. (1997). Behavioural responses of bacteria to light and oxygen. Arch. Microbiol. 168, 249-261. doi: 10.1007/s002030050496

Ashby, M. K. (2004). Survey of the number of two-component response regulator genes in the complete and annotated genome sequences of prokaryotes. FEMS Microbiol. Lett. 231, 277-281. doi: 10.1016/S0378-1097(04)00004-7

Austin, C. M., and Maier, R. J. (2013). Aconitase-mediated posttranscriptional regulation of Helicobacter pylori peptidoglycan deacetylase. J. Bacteriol. 195, 5316-5322. doi: 10.1128/JB.00720-13

Austin, C. M., Wang, G., and Maier, R. J. (2015). Aconitase functions as a pleiotropic posttranscriptional regulator in Helicobacter pylori. J. Bacteriol. 197, 3076-3086. doi: 10.1128/JB.00529- 15

Baker, M. D., Wolanin, P. M., and Stock, J. B. (2006). Systems biology of bacterial chemotaxis. Curr. Opin. Microbiol. 9, 187-192. doi: 10.1016/j.mib.2006.02.007

Bange, G., Petzold, G., Wild, K., Parlitz, R. O., and Sinning, I. (2007). The crystal structure of the third signal-recognition particle GTPase FlhF reveals a homodimer with bound GTP. Proc. Natl. Acad. Sci. U.S.A. 104, 13621-13625. doi: $10.1073 /$ pnas.0702570104

Barak, R., Giebel, I., and Eisenbach, M. (1996). The specificity of fumarate as a switching factor of the bacterial flagellar motor. Mol. Microbiol. 19, 139-144. doi: 10.1046/j.1365-2958.1996.365889.x

Barker, C. S., Inoue, T., Meshcheryakova, I. V., Kitanobo, S., and Samatey, F. A. (2016). Function of the conserved FHIPEP domain of the flagellar type III export apparatus, protein FlhA. Mol. Microbiol. 100, 278-288. doi: 10.1111/ mmi.13315

Barker, D. F., and Campbell, A. M. (1981). Genetic and biochemical characterization of the birA gene and its product: evidence for a direct role of biotin holoenzyme synthetase in repression of the biotin operon in Escherichia coli. J. Mol. Biol. 146, 469-492. doi: 10.1016/0022-2836(81)90043-7

Baron, S., Afanzar, O., and Eisenbach, M. (2017). Methylation-independent adaptation in chemotaxis of Escherichia coli involves acetylation-dependent speed adaptation. FEBS Lett. 591, 331-337. doi: 10.1002/1873-3468. 12537

Behrens, W., Schweinitzer, T., Mcmurry, J. L., Loewen, P. C., Buettner, F. F., Menz, S., et al. (2016). Localisation and protein-protein interactions of the Helicobacter pylori taxis sensor TlpD and their connection to metabolic functions. Sci. Rep. 6:23582. doi: $10.1038 /$ srep 23582

\section{AUTHOR CONTRIBUTIONS}

All authors wrote the manuscript jointly. AA and CJ revised the manuscript critically for timely content and structure. CJ developed the initial concept of the article and acquired funding. All authors edited, revised, and approved the final manuscript.

\section{ACKNOWLEDGMENTS}

We acknowledge the German Center for Infection Research (DZIF, projects 06.801 and 06.809) for funding. We also acknowledge financial support to CJ by grant Jo 344/5-1 from the Deutsche Forschungsgemeinschaft (DFG, German Research Foundation).

Bernard, R., Guiseppi, A., Chippaux, M., Foglino, M., and Denizot, F. (2007). Resistance to bacitracin in Bacillus subtilis: unexpected requirement of the $\mathrm{Bce} A \mathrm{~B} \mathrm{ABC}$ transporter in the control of expression of its own structural genes. J. Bacteriol. 189, 8636-8642. doi: 10.1128/JB.01132-07

Boll, J. M., and Hendrixson, D. R. (2013). A regulatory checkpoint during flagellar biogenesis in Campylobacter jejuni initiates signal transduction to activate transcription of flagellar genes. mBio 4:e00432-13. doi: 10.1128/mBio.00432- 13

Borrok, M. J., Kolonko, E. M., and Kiessling, L. L. (2008). Chemical probes of bacterial signal transduction reveal that repellents stabilize and attractants destabilize the chemoreceptor array. ACS Chem. Biol. 3, 101-109. doi: 10.1021/ cb700211s

Bourret, R. B., and Silversmith, R. E. (2010). Two-component signal transduction. Curr. Opin. Microbiol. 13, 113-115. doi: 10.1016/j.mib.2010.02.003

Brameyer, S., Rösch, T. C., El Andari, J., Hoyer, E., Schwarz, J., Graumann, P. L., et al. (2019). DNA-binding directs the localization of a membrane-integrated receptor of the ToxR family. Commun. Biol. 2:4. doi: 10.1038/s42003-018-02487

Briegel, A., Ladinsky, M. S., Oikonomou, C., Jones, C. W., Harris, M. J., Fowler, D. J., et al. (2014). Structure of bacterial cytoplasmic chemoreceptor arrays and implications for chemotactic signaling. eLife 3:e02151. doi: 10.7554/eLife.02151

Briegel, A., Ortega, D. R., Mann, P., Kjaer, A., Ringgaard, S., and Jensen, G. J. (2016). Chemotaxis cluster 1 proteins form cytoplasmic arrays in Vibrio cholerae and are stabilized by a double signaling domain receptor DosM. Proc. Natl. Acad. Sci. U.S.A. 113, 10412-10417. doi: 10.1073/pnas.1604693113

Buchner, S., Schlundt, A., Lassak, J., Sattler, M., and Jung, K. (2015). Structural and functional analysis of the signal-transducing linker in the $\mathrm{pH}$-responsive one-component system CadC of Escherichia coli. J. Mol. Biol. 427, 2548-2561. doi: 10.1016/j.jmb.2015.05.001

Buelow, D. R., and Raivio, T. L. (2010). Three (and more) component regulatory systems-auxiliary regulators of bacterial histidine kinases. Mol. Microbiol. 75, 547-566. doi: 10.1111/j.1365-2958.2009.06982.x

Buhrke, T., Lenz, O., Porthun, A., and Friedrich, B. (2004). The H2-sensing complex of Ralstonia eutropha: interaction between a regulatory [NiFe] hydrogenase and a histidine protein kinase. Mol. Microbiol. 51, 1677-1689. doi: 10.1111/j.1365-2958.2003.03933.x

Capra, E. J., and Laub, M. T. (2012). Evolution of two-component signal transduction systems. Annu. Rev. Microbiol. 66, 325-347. doi: 10.1146/ annurev-micro-092611-150039

Chevance, F. F., and Hughes, K. T. (2017). Case for the genetic code as a triplet of triplets. Proc. Natl. Acad. Sci. U.S.A. 114, 4745-4750. doi: 10.1073/pnas. 1614896114

Clemens, R., Zaschke-Kriesche, J., Khosa, S., and Smits, S. H. J. (2018). Insight into two ABC transporter families involved in lantibiotic resistance. Front. Mol. Biosci. 4:91. doi: 10.3389/fmolb.2017.00091

Cohen-Ben-Lulu, G. N., Francis, N. R., Shimoni, E., Noy, D., Davidov, Y., Prasad, K., et al. (2008). The bacterial flagellar switch complex is getting more complex. EMBO J. 27, 1134-1144. doi: 10.1038/emboj.2008.48 
Collins, K. D., Andermann, T. M., Draper, J., Sanders, L., Williams, S. M., Araghi, C., et al. (2016). The Helicobacter pylori CZB cytoplasmic chemoreceptor TlpD forms an autonomous polar chemotaxis signaling complex that mediates a tactic response to oxidative stress. J. Bacteriol. 198, 1563-1575. doi: 10.1128/ JB.00071-16

Commichau, F. M., and Stülke, J. (2015). Trigger enzymes: coordination of metabolism and virulence gene expression. Microbiol. Spectr. 3, 105-127. doi: 10.1128/microbiolspec.MBP-0010-2014

Coumes-Florens, S., Brochier-Armanet, C., Guiseppi, A., Denizot, F., and Foglino, M. (2011). A new highly conserved antibiotic sensing/resistance pathway in firmicutes involves an $\mathrm{ABC}$ transporter interplaying with a signal transduction system. PLoS One 6:e15951. doi: 10.1371/journal.pone.0015951

Dasgupta, N., Wolfgang, M. C., Goodman, A. L., Arora, S. K., Jyot, J., Lory, S., et al. (2003). A four-tiered transcriptional regulatory circuit controls flagellar biogenesis in Pseudomonas aeruginosa. Mol. Microbiol. 50, 809-824. doi: 10. 1046/j.1365-2958.2003.03740.x

Desai, S. K., and Kenney, L. J. (2017). To approximately P or Not to approximately $\mathrm{P}$ ? Non-canonical activation by two-component response regulators. Mol. Microbiol. 103, 203-213. doi: $10.1111 / \mathrm{mmi} .13532$

Deutscher, J. (2008). The mechanisms of carbon catabolite repression in bacteria. Curr. Opin. Microbiol. 11, 87-93. doi: 10.1016/j.mib.2008.02.007

Deutscher, J., Ake, F. M., Derkaoui, M., Zebre, A. C., Cao, T. N., Bouraoui, H., et al. (2014). The bacterial phosphoenolpyruvate:carbohydrate phosphotransferase system: regulation by protein phosphorylation and phosphorylation-dependent protein-protein interactions. Microbiol. Mol. Biol. Rev. 78, 231-256. doi: 10. 1128/MMBR.00001-14

Di Paolo, D., Afanzar, O., Armitage, J. P., and Berry, R. M. (2016). Singlemolecule imaging of electroporated dye-labelled CheY in live Escherichia coli. Philos. Trans. R. Soc. Lond B Biol. Sci. 371, 1-13. doi: 10.1098/rstb.2015. 0492

Dintner, S., Heermann, R., Fang, C., Jung, K., and Gebhard, S. (2014). A sensory complex consisting of an ATP-binding cassette transporter and a twocomponent regulatory system controls bacitracin resistance in Bacillus subtilis. J. Biol. Chem. 289, 27899-27910. doi: 10.1074/jbc.M114.596221

Dintner, S., Staron, A., Berchtold, E., Petri, T., Mascher, T., and Gebhard, S. (2011). Coevolution of $\mathrm{ABC}$ transporters and two-component regulatory systems as resistance modules against antimicrobial peptides in Firmicutes Bacteria. J. Bacteriol. 193, 3851-3862. doi: 10.1128/JB.05175-11

Dufour, Y. S., Fu, X., Hernandez-Nunez, L., and Emonet, T. (2014). Limits of feedback control in bacterial chemotaxis. PLoS Comput. Biol. 10:e1003694. doi: 10.1371/journal.pcbi.1003694

Edwards, J. C., Johnson, M. S., and Taylor, B. L. (2006). Differentiation between electron transport sensing and proton motive force sensing by the Aer and Tsr receptors for aerotaxis. Mol. Microbiol. 62, 823-837. doi: 10.1111/j.1365-2958. 2006.05411.x

Eisenreich, W., Heesemann, J., Rudel, T., and Goebel, W. (2015). Metabolic adaptations of intracellullar bacterial pathogens and their mammalian host cells during infection ("pathometabolism"). Microbiol. Spectr. 3, 27-58. doi: 10.1128/microbiolspec.MBP-0002-2014

Erhardt, M., Wheatley, P., Kim, E. A., Hirano, T., Zhang, Y., Sarkar, M. K., et al. (2017). Mechanism of type-III protein secretion: regulation of FlhA conformation by a functionally critical charged-residue cluster. Mol. Microbiol. 104, 234-249. doi: 10.1111/mmi.13623

Fiebig, A., Herrou, J., Willett, J., and Crosson, S. (2015). General stress signaling in the alphaproteobacteria. Annu. Rev. Genet. 49, 603-625. doi: 10.1146/annurevgenet-112414-054813

Francis, V. I., and Porter, S. L. (2019). Multikinase networks: two-component signaling networks integrating multiple stimuli. Annu. Rev. Microbiol. 73, 199-223. doi: 10.1146/annurev-micro-020518-115846

Fritz, G., Dintner, S., Treichel, N. S., Radeck, J., Gerland, U., Mascher, T., et al. (2015). A new way of sensing: need-based activation of antibiotic resistance by a flux-sensing mechanism. mBio 6:e00975. doi: 10.1128/mBio. 00975-15

Fritz, G., Koller, C., Burdack, K., Tetsch, L., Haneburger, I., Jung, K., et al. (2009). Induction kinetics of a conditional $\mathrm{pH}$ stress response system in Escherichia coli. J. Mol. Biol. 393, 272-286. doi: 10.1016/j.jmb.2009.08.037

Galperin, M. Y. (2018). What bacteria want. Environ. Microbiol. 20, 4221-4229. doi: $10.1111 / 1462-2920.14398$
Gao, R., and Stock, A. M. (2009). Biological insights from structures of twocomponent proteins. Annu. Rev. Microbiol. 63, 133-154. doi: 10.1146/annurev. micro.091208.073214

Garcia, D., Watts, K. J., Johnson, M. S., and Taylor, B. L. (2016). Delineating PASHAMP interaction surfaces and signalling-associated changes in the aerotaxis receptor Aer. Mol. Microbiol. 100, 156-172. doi: 10.1111/mmi.13308

García-Fontana, C., Reyes-Darias, J. A., Muñoz-Martínez, F., Alfonso, C., Morel, B., Ramos, J. L., et al. (2013). High specificity in CheR methyltransferase function CheR2 of Pseudomonas putida is essential for chemotaxis, whereas CheR1 is involved in biofilm formation. J. Biol. Chem. 288, 18987-18999. doi: 10.1074/jbc.M113.472605

Gardner, S. G., Johns, K. D., Tanner, R., and Mccleary, W. R. (2014). The PhoU protein from Escherichia coli interacts with PhoR, PstB, and metals to form a phosphate-signaling complex at the membrane. J. Bacteriol. 196, 1741-1752. doi: 10.1128/JB.00029-14

Gebhard, S. (2012). ABC transporters of antimicrobial peptides in Firmicutes bacteria - phylogeny, function and regulation. Mol. Microbiol. 86, 1295-1317. doi: $10.1111 / \mathrm{mmi} .12078$

Gebhard, S., and Mascher, T. (2011). Antimicrobial peptide sensing and detoxification modules: unravelling the regulatory circuitry of Staphylococcus aureus. Mol. Microbiol. 81, 581-587. doi: 10.1111/j.1365-2958.2011.07747.x

Glagolev, A. N. (1980). Reception of the energy level in bacterial taxis. J. Theor. Biol. 82, 171-185. doi: 10.1016/0022-5193(80)90097-1

Graf, S., Schmieden, D., Tschauner, K., Hunke, S., and Unden, G. (2014). The sensor kinase DctS forms a tripartite sensor unit with DctB and DctA for sensing C4-dicarboxylates in Bacillus subtilis. J. Bacteriol. 196, 1084-1093. doi: 10.1128/JB.01154-13

Groeneveld, M., Weme, R. G., Duurkens, R. H., and Slotboom, D. J. (2010). Biochemical characterization of the C4-dicarboxylate transporter DctA from Bacillus subtilis. J. Bacteriol. 192, 2900-2907. doi: 10.1128/JB.00136-10

Groisman, E. A. (2016). Feedback control of two-component regulatory systems. Annu. Rev. Microbiol. 70, 103-124. doi: 10.1146/annurev-micro-102215095331

Gunka, K., Newman, J. A., Commichau, F. M., Herzberg, C., Rodrigues, C., Hewitt, L., et al. (2010). Functional dissection of a trigger enzyme: mutations of the Bacillus subtilis glutamate dehydrogenase RocG that affect differentially its catalytic activity and regulatory properties. J. Mol. Biol. 400, 815-827. doi: 10.1016/j.jmb.2010.05.055

Haneburger, I., Eichinger, A., Skerra, A., and Jung, K. (2011). New insights into the signaling mechanism of the $\mathrm{pH}$-responsive, membrane-integrated transcriptional activator CadC of Escherichia coli. J. Biol. Chem. 286, 1068110689. doi: $10.1074 /$ jbc.M110.196923

Haneburger, I., Fritz, G., Jurkschat, N., Tetsch, L., Eichinger, A., Skerra, A., et al. (2012). Deactivation of the E. coli $\mathrm{pH}$ stress sensor CadC by cadaverine. J. Mol. Biol. 424, 15-27. doi: 10.1016/j.jmb.2012.08.023

Hauf, W., Schmid, K., Gerhardt, E. C., Huergo, L. F., and Forchhammer, K. (2016). Interaction of the nitrogen regulatory protein $\mathrm{GlnB}$ (PII) with biotin carboxyl carrier protein (BCCP) Controls Acetyl-CoA Levels in the Cyanobacterium Synechocystis sp. PCC 6803. Front. Microbiol. 7:1700. doi: 10.3389/fmicb.2016. 01700

Herrou, J., Foreman, R., Fiebig, A., and Crosson, S. (2010). A structural model of anti-anti-sigma inhibition by a two-component receiver domain: the PhyR stress response regulator. Mol. Microbiol. 78, 290-304. doi: 10.1111/j.13652958.2010.07323.x

Hervas, A. B., Canosa, I., Little, R., Dixon, R., and Santero, E. (2009). NtrCdependent regulatory network for nitrogen assimilation in Pseudomonas putida. J. Bacteriol. 191, 6123-6135. doi: 10.1128/JB.00744-09

Hickman, J. W., Tifrea, D. F., and Harwood, C. S. (2005). A chemosensory system that regulates biofilm formation through modulation of cyclic diguanylate levels. Proc. Natl. Acad. Sci. U.S.A. 102, 14422-14427. doi: 10.1073/pnas. 0507170102

Hiremath, G., Hyakutake, A., Yamamoto, K., Ebisawa, T., Nakamura, T., Nishiyama, S., et al. (2015). Hypoxia-induced localization of chemotaxis-related signaling proteins in Vibrio cholerae. Mol. Microbiol. 95, 780-790. doi: 10.1111/ mmi. 12887

Hsieh, Y. J., and Wanner, B. L. (2010). Global regulation by the seven-component Pi signaling system. Curr. Opin. Microbiol. 13, 198-203. doi: 10.1016/j.mib.2010. 01.014 
Huergo, L. F., Chandra, G., and Merrick, M. (2013). P(II) signal transduction proteins: nitrogen regulation and beyond. FEMS Microbiol. Rev. 37, 251-283. doi: 10.1111/j.1574-6976.2012.00351.x

Inaba, J., Thornton, J., Huergo, L. F., Monteiro, R. A., Klassen, G., Pedrosa Fde, O., et al. (2015). Mutational analysis of $G \ln B$ residues critical for NifA activation in Azospirillum brasilense. Microbiol. Res. 171, 65-72. doi: 10.1016/j.micres.2014. 12.005

Irazoki, O., Mayola, A., Campoy, S., and Barbe, J. (2016). SOS system induction inhibits the assembly of chemoreceptor signaling clusters in Salmonella enterica. PLoS One 11:e0146685. doi: 10.1371/journal.pone.0146685

Jacobi, S., Schade, R., and Heuner, K. (2004). Characterization of the alternative sigma factor sigma54 and the transcriptional regulator FleQ of Legionella pneumophila, which are both involved in the regulation cascade of flagellar gene expression. J. Bacteriol. 186:2540. doi: 10.1128/JB.186.9.2540-2547.2004

Jeffery, C. J. (1999). Moonlighting proteins. Trends Biochem. Sci. 24, 8-11. doi: 10.1016/s0968-0004(98)01335-8

Jeffery, C. J. (2014). An introduction to protein moonlighting. Biochem. Soc. Trans. 42, 1679-1683. doi: 10.1042/BST20140226

Jeffery, C. J. (2019). An enzyme in the test tube, and a transcription factor in the cell: moonlighting proteins and cellular factors that affect their behavior. Protein Sci. 28, 1233-1238. doi: 10.1002/pro.3645

Johnson, A. S., Van Horck, S., and Lewis, P. J. (2004). Dynamic localization of membrane proteins in Bacillus subtilis. Microbiology 150, 2815-2824. doi: 10. 1099/mic.0.27223-0

Josenhans, C., Niehus, E., Amersbach, S., Hörster, A., Betz, C., Drescher, B., et al. (2002). Functional characterization of the antagonistic flagellar late regulators FliA and FlgM of Helicobacter pylori and their effects on the H. pylori transcriptome. Mol. Microbiol. 43, 307-322. doi: 10.1046/j.1365-2958.2002. 02765.x

Joyet, P., Bouraoui, H., Ake, F. M., Derkaoui, M., Zebre, A. C., Cao, T. N., et al. (2013). Transcription regulators controlled by interaction with enzyme IIB components of the phosphoenolpyruvate: sugar phosphotransferase system. Biochim. Biophys. Acta 1834, 1415-1424. doi: 10.1016/j.bbapap.2013.01.004

Jugder, B. E., Chen, Z., Ping, D. T., Lebhar, H., Welch, J., and Marquis, C. P. (2015). An analysis of the changes in soluble hydrogenase and global gene expression in Cupriavidus necator (Ralstonia eutropha) H16 grown in heterotrophic diauxic batch culture. Microb. Cell Fact. 14, 1-11. doi: 10.1186/s12934-0150226-4

Kamp, H. D., and Higgins, D. E. (2011). A protein thermometer controls temperature-dependent transcription of flagellar motility genes in Listeria monocytogenes. PLoS Pathog. 7:e1002153. doi: 10.1371/journal.ppat.1002153

Karstens, K., Zschiedrich, C. P., Bowien, B., Stülke, J., and Görke, B. (2014). Phosphotransferase protein EIIANtr interacts with SpoT, a key enzyme of the stringent response, in Ralstonia eutropha H16. Microbiology 160, 711-722. doi: 10.1099/mic.0.075226-0

Kazmierczak, B. I., and Hendrixson, D. R. (2013). Spatial and numerical regulation of flagellar biosynthesis in polarly flagellated bacteria. Mol. Microbiol. 88, 655-663. doi: 10.1111/mmi.12221

Kiley, P. J., and Beinert, H. (2003). The role of Fe-S proteins in sensing and regulation in bacteria. Curr. Opin. Microbiol. 6, 181-185. doi: 10.1016/s13695274(03)00039-0

Kirby, J. R. (2009). Chemotaxis-like regulatory systems: unique roles in diverse bacteria. Annu. Rev. Microbiol. 63, 45-59. doi: 10.1146/annurev.micro.091208. 073221

Kleefeld, A., Ackermann, B., Bauer, J., Krämer, J., and Unden, G. (2009). The fumarate/succinate antiporter DcuB of Escherichia coli is a bifunctional protein with sites for regulation of DcuS-dependent gene expression. J. Biol. Chem. 284, 265-275. doi: 10.1074/jbc.M807856200

Kneuper, H., Janausch, I. G., Vijayan, V., Zweckstetter, M., Bock, V., Griesinger, C., et al. (2005). The nature of the stimulus and of the fumarate binding site of the fumarate sensor DcuS of Escherichia coli. J. Biol. Chem. 280, 20596-20603. doi: 10.1074/jbc.M502015200

Koganitsky, A., Tworowski, D., Dadosh, T., Cecchini, G., and Eisenbach, M. (2019). A mechanism of modulating the direction of flagellar rotation in bacteria by fumarate and fumarate reductase. J. Mol. Biol. 431, 3662-3676. doi: 10.1016/j. jmb.2019.08.001

Kondo, S., Homma, M., and Kojima, S. (2017). Analysis of the GTPase motif of FlhF in the control of the number and location of polar flagella in Vibrio alginolyticus. Biophys. Physicobiol. 14, 173-181. doi: 10.2142/biophysico.14.0_ 173

Krell, T., Lacal, J., Busch, A., Silva-Jimenez, H., Guazzaroni, M. E., and Ramos, J. L. (2010). Bacterial sensor kinases: diversity in the recognition of environmental signals. Annu. Rev. Microbiol. 64, 539-559. doi: 10.1146/annurev.micro.112408. 134054

Lee, Y. T., and Wang, M. C. (2019). The bacterivore's solution: fight and flight to promote survival. Dev. Cell 49, 7-9. doi: 10.1016/j.devcel.2019.03.021

Lenn, T., Leake, M. C., and Mullineaux, C. W. (2008). Are Escherichia coli OXPHOS complexes concentrated in specialized zones within the plasma membrane? Biochem. Soc. Trans. 36, 1032-1036. doi: 10.1042/BST036 1032

Lertsethtakarn, P., Ottemann, K. M., and Hendrixson, D. R. (2011). Motility and chemotaxis in Campylobacter and Helicobacter. Annu. Rev. Microbiol. 65, 389-410. doi: 10.1146/annurev-micro-090110-102908

Lindner, E., and White, S. H. (2014). Topology, dimerization, and stability of the single-span membrane protein CadC. J. Mol. Biol. 426, 2942-2957. doi: 10.1016/j.jmb.2014.06.006

Liu, L. K., Becker, D. F., and Tanner, J. J. (2017). Structure, function, and mechanism of proline utilization A (PutA). Arch. Biochem. Biophys. 632, 142157. doi: 10.1016/j.abb.2017.07.005

Llorente-Garcia, I., Lenn, T., Erhardt, H., Harriman, O. L., Liu, L. N., Robson, A., et al. (2014). Single-molecule in vivo imaging of bacterial respiratory complexes indicates delocalized oxidative phosphorylation. Biochim. Biophys. Acta 1837, 811-824. doi: 10.1016/j.bbabio.2014.01.020

Loh, J. T., Gupta, S. S., Friedman, D. B., Krezel, A. M., and Cover, T. L. (2010). Analysis of protein expression regulated by the Helicobacter pylori ArsRS twocomponent signal transduction system. J. Bacteriol. 192, 2034-2043. doi: 10. 1128/JB.01703-08

Lopes, J. G., and Sourjik, V. (2018). Chemotaxis of Escherichia coli to major hormones and polyamines present in human gut. ISME J. 12, 2736-2747. doi: 10.1038/s41396-018-0227-5

Löscher, S., Gebler, A., Stein, M., Sanganas, O., Buhrke, T., Zebger, I., et al. (2010). Protein-protein complex formation affects the Ni-Fe and Fe-S centers in the H2-sensing regulatory hydrogenase from Ralstonia eutropha H16. Chemphyschem 11, 1297-1306. doi: 10.1002/cphc.200901007

Lushchak, O. V., Piroddi, M., Galli, F., and Lushchak, V. I. (2014). Aconitase post-translational modification as a key in linkage between Krebs cycle, iron homeostasis, redox signaling, and metabolism of reactive oxygen species. Redox Rep. 19, 8-15. doi: 10.1179/1351000213Y.0000000073

Luttmann, D., Göpel, Y., and Görke, B. (2015). Cross-talk between the canonical and the nitrogen-related phosphotransferase systems modulates synthesis of the KdpFABC potassium transporter in Escherichia coli. J. Mol. Microbiol. Biotechnol. 25, 168-177. doi: 10.1159/000375497

Mairet, F. (2018). A biomolecular proportional integral controller based on feedback regulations of protein level and activity. R. Soc. Open Sci. 5:171966. doi: $10.1098 /$ rsos. 171966

Marcus, E. A., Sachs, G., Wen, Y., and Scott, D. R. (2016). Phosphorylationdependent and phosphorylation-independent regulation of Helicobacter pylori acid acclimation by the Ars RS two-component System. Helicobacter 21, 69-81. doi: 10.1111/hel.12235

Mascher, T. (2014). Bacterial (intramembrane-sensing) histidine kinases: signal transfer rather than stimulus perception. Trends Microbiol. 22, 559-565. doi: 10.1016/j.tim.2014.05.006

Mascher, T., Helmann, J. D., and Unden, G. (2006). Stimulus perception in bacterial signal-transducing histidine kinases. Microbiol. Mol. Biol. Rev. 70, 910-938. doi: 10.1128/MMBR.00020-06

Masilamani, R., Cian, M. B., and Dalebroux, Z. D. (2018). Salmonella Tol-Pal reduces outer membrane glycerophospholipid levels for envelope homeostasis and survival during bacteremia. Infect. Immun. 86:e00173-18. doi: 10.1128/IAI. 00173-18

Matson, J. S., Livny, J., and Dirita, V. J. (2017). A putative Vibrio cholerae twocomponent system controls a conserved periplasmic protein in response to the antimicrobial peptide polymyxin B. PLoS One 12:e0186199. doi: 10.1371/ journal.pone.0186199

Mauriello, E. M. F., Jones, C., Moine, A., and Armitage, J. P. (2018). Cellular targeting and segregation of bacterial chemosensory systems. FEMS Microbiol. Rev. 42, 462-476. doi: 10.1093/femsre/fuy015 
May, K. L., Lehman, K. M., Mitchell, A. M., and Grabowicz, M. (2019). A stress response monitoring lipoprotein trafficking to the outer membrane. mBio 10:e0618-19. doi: 10.1128/mBio.00618-19

Mayola, A., Irazoki, O., Martinez, I. A., Petrov, D., Menolascina, F., Stocker, R., et al. (2014). RecA protein plays a role in the chemotactic response and chemoreceptor clustering of Salmonella enterica. PLoS One 9:e105578. doi: 10.1371/journal.pone.0105578

Minamino, T., Kinoshita, M., Inoue, Y., Morimoto, Y. V., Ihara, K., Koya, S., et al. (2016a). FliH and FliI ensure efficient energy coupling of flagellar type III protein export in Salmonella. Microbiologyopen 5, 424-435. doi: 10.1002/ mbo3.340

Minamino, T., Morimoto, Y. V., Hara, N., Aldridge, P. D., and Namba, K. (2016b). The bacterial flagellar type III export gate complex is a dual fuel engine that can use both $\mathrm{H}+$ and $\mathrm{Na}+$ for flagellar protein export. PLoS Pathog. 12:e1005495. doi: 10.1371/journal.ppat.1005495

Minamino, T., and Macnab, R. M. (1999). Components of the Salmonella flagellar export apparatus and classification of export substrates. J. Bacteriol. 181:1388.

Mirouze, N., Bidnenko, E., Noirot, P., and Auger, S. (2015). Genome-wide mapping of TnrA-binding sites provides new insights into the TnrA regulon in Bacillus subtilis. Microbiologyopen 4, 423-435. doi: 10.1002/mbo3.249

Monahan, L. G., and Harry, E. J. (2016). You are what you eat: metabolic control of bacterial division. Trends Microbiol. 24, 181-189. doi: 10.1016/j.tim.2015. 11.007

Monzel, C., Degreif-Dunnwald, P., Gropper, C., Griesinger, C., and Unden, G. (2013). The cytoplasmic PASC domain of the sensor kinase DcuS of Escherichia coli: role in signal transduction, dimer formation, and DctA interaction. Microbiologyopen 2, 912-927. doi: 10.1002/mbo3.127

Mukherjee, T., Elmas, M., Vo, L., Alexiades, V., Hong, T., and Alexandre, G. (2019). Multiple CheY homologs control swimming reversals and transient pauses in Azospirillum brasilense. Biophys. J. 116, 1527-1537. doi: 10.1016/j.bpj.2019. 03.006

Muok, A. R., Briegel, A., and Crane, B. R. (2019a). Regulation of the chemotaxis histidine kinase CheA: a structural perspective. Biochim. Biophys. Acta Biomembr. 1862:183030. doi: 10.1016/j.bbamem.2019.183030

Muok, A. R., Deng, Y., Gumerov, V. M., Chong, J. E., Derosa, J. R., Kurniyati, K., et al. (2019b). A di-iron protein recruited as an Fe [II] and oxygen sensor for bacterial chemotaxis functions by stabilizing an iron-peroxy species. Proc. Natl. Acad. Sci. U.S.A. 116, 14955-14960. doi: 10.1073/pnas.1904234116

Muzamal, U., Gomez, D., Kapadia, F., and Golemi-Kotra, D. (2014). Diversity of two-component systems: insights into the signal transduction mechanism by the Staphylococcus aureus two-component system GraSR. F1000Res 3:252. doi: 10.12688/f1000research.5512.2

Neira, J. L., Hornos, F., Cozza, C., Camara-Artigas, A., Abian, O., and VelazquezCampoy, A. (2018). The histidine phosphocarrier protein, HPr, binds to the highly thermostable regulator of sigma D protein, Rsd, and its isolated helical fragments. Arch. Biochem. Biophys. 639, 26-37. doi: 10.1016/j.abb.2017.12.017

Nesper, J., Hug, I., Kato, S., Hee, C.-S., Habazettl, J. M., Manfredi, P., et al. (2017). Cyclic di-GMP differentially tunes a bacterial flagellar motor through a novel class of CheY-like regulators. elife 6:e28842. doi: 10.7554/eLife.28842

Neumann, S., Grosse, K., and Sourjik, V. (2012). Chemotactic signaling via carbohydrate phosphotransferase systems in Escherichia coli. Proc. Natl. Acad. Sci. U.S.A. 109, 12159-12164. doi: 10.1073/pnas.1205307109

Niehus, E., Gressmann, H., Ye, F., Schlapbach, R., Dehio, M., Dehio, C., et al. (2004). Genome-wide analysis of transcriptional hierarchy and feedback regulation in the flagellar system of Helicobacter pylori. Mol. Microbiol. 52, 947-961. doi: 10.1111/j.1365-2958.2004.04006.x

Nieto, V., Partridge, J. D., Severin, G., Lai, R.-Z., Waters, C., Parkinson, J. S., et al. (2019). Under elevated c-di-GMP in E. coli, YcgR alters flagellar motor bias and speed sequentially, with additional negative control of the flagellar regulon via the adaptor protein RssB. J. Bacteriol. 202:e00578-19. doi: 10.1128/JB. 00578-19

Nishikino, T., Hijikata, A., Miyanoiri, Y., Onoue, Y., Kojima, S., Shirai, T., et al. (2018). Rotational direction of flagellar motor from the conformation of FliG middle domain in marine Vibrio. Sci. Rep. 8:17793. doi: 10.1038/s41598-01835902-6

Osman, D., Martini, M. A., Foster, A. W., Chen, J., Scott, A. J. P., Morton, R. J., et al. (2019). Bacterial sensors define intracellular free energies for correct enzyme metalation. Nat. Chem. Biol. 15, 241-249. doi: 10.1038/s41589-018-0211-4
Ouyang, J., Tian, X. L., Versey, J., Wishart, A., and Li, Y. H. (2010). The BceABRS four-component system regulates the bacitracin-induced cell envelope stress response in Streptococcus mutans. Antimicrob. Agents Chemother. 54, 38953906. doi: 10.1128/AAC.01802-09

Packer, H. L., and Armitage, J. P. (2000a). Behavioral responses of Rhodobacter sphaeroides to linear gradients of the nutrients succinate and acetate. Appl. Environ. Microbiol. 66, 5186-5191. doi: 10.1128/aem.66.12.5186-5191. 2000

Packer, H. L., and Armitage, J. P. (2000b). Inverted behavioural responses in wildtype Rhodobacter sphaeroides to temporal stimuli. FEMS Microbiol. Lett. 189, 299-304. doi: 10.1111/j.1574-6968.2000.tb09247.x

Papenfort, K., and Bassler, B. L. (2016). Quorum sensing signal-response systems in Gram-negative bacteria. Nat. Rev. Microbiol. 14, 576-588. doi: 10.1038/ nrmicro.2016.89

Pappalardo, L., Janausch, I. G., Vijayan, V., Zientz, E., Junker, J., Peti, W., et al. (2003). The NMR structure of the sensory domain of the membranous twocomponent fumarate sensor (histidine protein kinase) DcuS of Escherichia coli. J. Biol. Chem. 278, 39185-39188. doi: 10.1074/jbc.C300344200

Parkinson, J. S., Hazelbauer, G. L., and Falke, J. J. (2015). Signaling and sensory adaptation in Escherichia coli chemoreceptors: 2015 update. Trends Microbiol. 23, 257-266. doi: 10.1016/j.tim.2015.03.003

Pflock, M., Finsterer, N., Joseph, B., Mollenkopf, H., Meyer, T. F., and Beier, D. (2006). Characterization of the ArsRS regulon of Helicobacter pylori, involved in acid adaptation. J. Bacteriol. 188, 3449-3462. doi: 10.1128/JB.188.10.34493462.2006

Porter, S. L., Wadhams, G. H., and Armitage, J. P. (2011). Signal processing in complex chemotaxis pathways. Nat. Rev. Microbiol. 9, 153-165. doi: 10.1038/ nrmicro2505

Radeck, J., Fritz, G., and Mascher, T. (2017). The cell envelope stress response of Bacillus subtilis: from static signaling devices to dynamic regulatory network. Curr. Genet. 63, 79-90. doi: 10.1007/s00294-016-0624-0

Randazzo, P., Aucouturier, A., Delumeau, O., and Auger, S. (2017). Revisiting the in vivo GlnR-binding sites at the genome scale in Bacillus subtilis. BMC Res. Notes 10:422. doi: 10.1186/s13104-017-2703-9

Rauschmeier, M., Schüppel, V., Tetsch, L., and Jung, K. (2014). New insights into the interplay between the lysine transporter LysP and the $\mathrm{pH}$ sensor CadC in Escherichia coli. J. Mol. Biol. 426, 215-229. doi: 10.1016/j.jmb.2013.09.017

Rebbapragada, A., Johnson, M. S., Harding, G. P., Zuccarelli, A. J., Fletcher, H. M., Zhulin, I. B., et al. (1997). The Aer protein and the serine chemoreceptor Tsr independently sense intracellular energy levels and transduce oxygen, redox, and energy signals for Escherichia coli behavior. Proc. Natl. Acad. Sci. U.S.A. 94, 10541-10546. doi: 10.1073/pnas.94.20.10541

Ringgaard, S., Hubbard, T., Mandlik, A., Davis, B. M., and Waldor, M. K. (2015). RpoS and quorum sensing control expression and polar localization of Vibrio cholerae chemotaxis cluster III proteins in vitro and in vivo. Mol. Microbiol. 97, 660-675. doi: 10.1111/mmi.13053

Ringgaard, S., Yang, W., Alvarado, A., Schirner, K., and Briegel, A. (2018). Chemotaxis arrays in Vibrio species and their intracellular positioning by the ParC/ParP system. J. Bacteriol. 200:e00793-17. doi: 10.1128/JB.00793-17

Rivera-Chavez, F., Lopez, C. A., Zhang, L. F., Garcia-Pastor, L., Chavez-Arroyo, A., Lokken, K. L., et al. (2016). Energy taxis toward host-derived nitrate supports a Salmonella pathogenicity Island 1-independent mechanism of invasion. mBio 7:e00960-16. doi: 10.1128/mBio.00960-16

Rivera-Chavez, F., Winter, S. E., Lopez, C. A., Xavier, M. N., Winter, M. G., Nuccio, S. P., et al. (2013). Salmonella uses energy taxis to benefit from intestinal inflammation. PLoS Pathog. 9:e1003267. doi: 10.1371/journal.ppat.1003267

Russell, G., and Lightman, S. (2019). The human stress response. Nat. Rev. Endocrinol. 15, 525-534. doi: 10.1038/s41574-019-0228-0

Rust, M., Borchert, S., Niehus, E., Kuehne, S. A., Gripp, E., Bajceta, A., et al. (2009). The Helicobacter pylori anti-sigma factor FlgM is predominantly cytoplasmic and cooperates with the flagellar basal body protein FlhA. J. Bacteriol. 191, 4824-4834. doi: 10.1128/JB.00018-09

Samanta, D., Widom, J., Borbat, P. P., Freed, J. H., and Crane, B. R. (2016). Bacterial energy sensor Aer modulates the activity of the chemotaxis kinase CheA based on the redox state of the flavin cofactor. J. Biol. Chem. 291, 25809-25814. doi: 10.1074/jbc.C116.757492

Scheu, P. D., Steinmetz, P. A., Dempwolff, F., Graumann, P. L., and Unden, G. (2014). Polar localization of a tripartite complex of the two-component system 
DcuS/DcuR and the transporter DctA in Escherichia coli depends on the sensor kinase DcuS. PLoS One 9:e115534. doi: 10.1371/journal.pone.0115534

Schmitz, A., Josenhans, C., and Suerbaum, S. (1997). Cloning and characterization of the Helicobacter pylori flbA gene, which codes for a membrane protein involved in coordinated expression of flagellar genes. J. Bacteriol. 179, 987-997. doi: 10.1128/jb.179.4.987-997.1997

Schweinitzer, T., and Josenhans, C. (2010). Bacterial energy taxis: a global strategy? Arch. Microbiol. 192, 507-520. doi: 10.1007/s00203-010-0575-7

Schweinitzer, T., Mizote, T., Ishikawa, N., Dudnik, A., Inatsu, S., Schreiber, S., et al. (2008). Functional characterization and mutagenesis of the proposed behavioral sensor TlpD of Helicobacter pylori. J. Bacteriol. 190, 3244-3255. doi: 10.1128/JB.01940-07

Shen, A., Kamp, H. D., Gründling, A., and Higgins, D. E. (2006). A bifunctional O-GlcNAc transferase governs flagellar motility through anti-repression. Genes Dev. 20, 3283-3295. doi: 10.1101/gad.1492606

Somavanshi, R., Ghosh, B., and Sourjik, V. (2016). Sugar influx sensing by the phosphotransferase system of Escherichia coli. PLoS Biol. 14:e2000074. doi: 10.1371/journal.pbio.2000074

Stannek, L., Thiele, M. J., Ischebeck, T., Gunka, K., Hammer, E., Volker, U., et al. (2015). Evidence for synergistic control of glutamate biosynthesis by glutamate dehydrogenases and glutamate in Bacillus subtilis. Environ. Microbiol. 17, 3379-3390. doi: 10.1111/1462-2920.12813

Steinmetz, P. A., Wörner, S., and Unden, G. (2014). Differentiation of DctA and DcuS function in the DctA/DcuS sensor complex of Escherichia coli: function of DctA as an activity switch and of DcuS as the C4-dicarboxylate sensor. Mol. Microbiol. 94, 218-229. doi: 10.1111/mmi.12759

Strecker, A., Schubert, C., Zedler, S., Steinmetz, P., and Unden, G. (2018). DcuA of aerobically grown Escherichia coli serves as a nitrogen shuttle (Laspartate/fumarate) for nitrogen uptake. Mol. Microbiol. 109, 801-811. doi: $10.1111 / \mathrm{mmi} .14074$

Sule, N., Pasupuleti, S., Kohli, N., Menon, R., Dangott, L. J., Manson, M. D., et al. (2017). The norepinephrine metabolite 3,4-Dihydroxymandelic acid is produced by the commensal microbiota and promotes chemotaxis and virulence gene expression in enterohemorrhagic Escherichia coli. Infect. Immun. 85:e00431-17. doi: 10.1128/IAI.00431-17

Tang, Y., Guest, J. R., Artymiuk, P. J., and Green, J. (2005). Switching aconitase $\mathrm{B}$ between catalytic and regulatory modes involves iron-dependent dimer formation. Mol. Microbiol. 56, 1149-1158. doi: 10.1111/j.1365-2958.2005. 04610.x

Tang, Y., Guest, J. R., Artymiuk, P. J., Read, R. C., and Green, J. (2004). Posttranscriptional regulation of bacterial motility by aconitase proteins. Mol. Microbiol. 51, 1817-1826. doi: 10.1111/j.1365-2958.2003.03954.x

Taylor, B. L., Zhulin, I. B., and Johnson, M. S. (1999). Aerotaxis and other energysensing behavior in bacteria. Annu. Rev. Microbiol. 53, 103-128. doi: 10.1146/ annurev.micro.53.1.103

Terahara, N., Inoue, Y., Kodera, N., Morimoto, Y. V., Uchihashi, T., Imada, K., et al. (2018). Insight into structural remodeling of the FlhA ring responsible for bacterial flagellar type III protein export. Sci. Adv. 4:eaao7054. doi: 10.1126/ sciadv.aao7054

Tetsch, L., and Jung, K. (2009). The regulatory interplay between membraneintegrated sensors and transport proteins in bacteria. Mol. Microbiol. 73, 982-991. doi: 10.1111/j.1365-2958.2009.06847.x

Tetsch, L., Koller, C., Haneburger, I., and Jung, K. (2008). The membraneintegrated transcriptional activator CadC of Escherichia coli senses lysine indirectly via the interaction with the lysine permease LysP. Mol. Microbiol. 67, 570-583. doi: 10.1111/j.1365-2958.2007.06070.x

Tsang, J., Hirano, T., Hoover, T. R., and Mcmurry, J. L. (2015). Helicobacter pylori FlhA binds the sensor kinase and flagellar gene regulatory protein FlgS with high affinity. J. Bacteriol. 197, 1886-1892. doi: 10.1128/JB. 02610-14

Tsang, J., Smith, T. G., Pereira, L. E., and Hoover, T. R. (2013). Insertion mutations in Helicobacter pylori flhA reveal strain differences in RpoNdependent gene expression. Microbiology 159, 58-67. doi: 10.1099/mic.0. 059063-0

Tschauner, K., Hörnschemeyer, P., Müller, V. S., and Hunke, S. (2014). Dynamic interaction between the CpxA sensor kinase and the periplasmic accessory protein CpxP mediates signal recognition in E. coli. PLoS One 9:e107383. doi: 10.1371/journal.pone. 0107383
Unden, G., Wörner, S., and Monzel, C. (2016). Cooperation of secondary transporters and sensor kinases in transmembrane signalling: the DctA/DcuS and DcuB/DcuS sensor complexes of Escherichia coli. Adv. Microb. Physiol. 68, 139-167. doi: 10.1016/bs.ampbs.2016.02.003

Västermark, A., and Saier, M. H. Jr. (2014). The involvement of transport proteins in transcriptional and metabolic regulation. Curr. Opin. Microbiol. 18, 8-15. doi: 10.1016/j.mib.2014.01.002

Vuppada, R. K., Hansen, C. R., Strickland, K. A. P., Kelly, K. M., and Mccleary, W. R. (2018). Phosphate signaling through alternate conformations of the PstSCAB phosphate transporter. BMC Microbiol. 18:8. doi: 10.1186/s12866017-1126-z

Wanner, B. L., and Wilmes-Riesenberg, M. R. (1992). Involvement of phosphotransacetylase, acetate kinase, and acetyl phosphate synthesis in control of the phosphate regulon in Escherichia coli. J. Bacteriol. 174, 2124-2130. doi: 10.1128/jb.174.7.2124-2130.1992

Ward, E., Kim, E. A., Panushka, J., Botelho, T., Meyer, T., Kearns, D. B., et al. (2019). Organization of the flagellar switch complex of Bacillus subtilis. J. Bacteriol. 201:e00626-18. doi: 10.1128/JB.00626-18

Whiteley, M., Diggle, S. P., and Greenberg, E. P. (2017). Progress in and promise of bacterial quorum sensing research. Nature 551, 313-320. doi: 10.1038/ nature24624

Wiech, E. M., Cheng, H.-P., and Singh, S. M. (2015). Molecular modeling and computational analyses suggests that the Sinorhizobium meliloti periplasmic regulator protein ExoR adopts a superhelical fold and is controlled by a unique mechanism of proteolysis. Protein Sci. 24, 319-327. doi: 10.1002/pro.2616

Willett, J. W., and Crosson, S. (2017). Atypical modes of bacterial histidine kinase signaling. Mol. Microbiol. 103, 197-202. doi: 10.1111/mmi.13525

Winter, S. E., Thiennimitr, P., Winter, M. G., Butler, B. P., Huseby, D. L., Crawford, R. W., et al. (2010). Gut inflammation provides a respiratory electron acceptor for Salmonella. Nature 467, 426-429. doi: 10.1038/nature09415

Witan, J., Bauer, J., Wittig, I., Steinmetz, P. A., Erker, W., and Unden, G. (2012). Interaction of the Escherichia coli transporter DctA with the sensor kinase DcuS: presence of functional DctA/DcuS sensor units. Mol. Microbiol. 85, 846-861. doi: 10.1111/j.1365-2958.2012.08143.x

Wörner, S., Surmann, K., Ebert-Jung, A., Volker, U., Hammer, E., and Unden, G. (2018). Cellular Concentrations of the transporters DctA and DcuB and the sensor DcuS of Escherichia coli and the contributions of free and complexed DcuS to transcriptional regulation by DcuR. J. Bacteriol. 200:e06612-17. doi: 10.1128/JB.00612-17

Wray, L. V. Jr., Zalieckas, J. M., and Fisher, S. H. (2001). Bacillus subtilis glutamine synthetase controls gene expression through a protein-protein interaction with transcription factor TnrA. Cell 107, 427-435. doi: 10.1016/s0092-8674(01) 00572-4

Wu, K., Walukiewicz, H. E., Glekas, G. D., Ordal, G. W., and Rao, C. V. (2011). Attractant binding induces distinct structural changes to the polar and lateral signaling clusters in Bacillus subtilis chemotaxis. J. Biol. Chem. 286, 2587-2595. doi: $10.1074 /$ jbc.M110.188664

Wuichet, K., and Zhulin, I. B. (2010). Origins and diversification of a complex signal transduction system in prokaryotes. Sci. Signal. 3:ra50. doi: 10.1126/ scisignal.2000724

Xie, Z., Ulrich, L. E., Zhulin, I. B., and Alexandre, G. (2010). PAS domain containing chemoreceptor couples dynamic changes in metabolism with chemotaxis. Proc. Natl. Acad. Sci. U.S.A. 107, 2235-2240. doi: 10.1073/pnas. 0910055107

Xiong, Y., Yang, Z., Zhang, J., Li, J., Chen, P., and Xiang, Y. (2019). Panning using a phage-displayed random peptide library to identify peptides that antagonize the Helicobacter pylori ArsS acid-sensing domain. Microb. Pathog. 135:103614. doi: 10.1016/j.micpath.2019.103614

$\mathrm{Xu}, \mathrm{D}$., Jia, R., Li, Y., and Gu, T. (2017). Advances in the treatment of problematic industrial biofilms. World J. Microbiol. Biotechnol. 33, 1-10. doi: 10.1007/ s11274-016-2203-4

Zarbiv, G., Li, H., Wolf, A., Cecchini, G., Caplan, S. R., Sourjik, V., et al. (2012). Energy complexes are apparently associated with the switch-motor complex of bacterial flagella. J. Mol. Biol. 416, 192-207. doi: 10.1016/j.jmb.2011.12.027

Zhang, Y., Pohlmann, E. L., Serate, J., Conrad, M. C., and Roberts, G. P. (2010). Mutagenesis and functional characterization of the four domains of $\mathrm{GlnD}$, a bifunctional nitrogen sensor protein. J. Bacteriol. 192, 2711-2721. doi: 10.1128/ JB.01674-09 
Zimmer, D. P., Soupene, E., Lee, H. L., Wendisch, V. F., Khodursky, A. B., Peter, B. J., et al. (2000). Nitrogen regulatory protein C-controlled genes of Escherichia coli: scavenging as a defense against nitrogen limitation. Proc. Natl. Acad. Sci. U.S.A. 97, 14674-14679. doi: 10.1073/pnas.97.26.14674

Zschiedrich, C. P., Keidel, V., and Szurmant, H. (2016). Molecular mechanisms of two-component signal transduction. J. Mol. Biol. 428, 3752-3775. doi: 10.1016/ j.jmb.2016.08.003

Zusman, D. R., Scott, A. E., Yang, Z., and Kirby, J. R. (2007). Chemosensory pathways, motility and development in Myxococcus xanthus. Nat. Rev. Microbiol. 5, 862-872. doi: 10.1038/nrmicro1770
Conflict of Interest: The authors declare that the research was conducted in the absence of any commercial or financial relationships that could be construed as a potential conflict of interest.

Copyright $\odot 2020$ Alvarado, Behrens and Josenhans. This is an open-access article distributed under the terms of the Creative Commons Attribution License (CC BY). The use, distribution or reproduction in other forums is permitted, provided the original author(s) and the copyright owner(s) are credited and that the original publication in this journal is cited, in accordance with accepted academic practice. No use, distribution or reproduction is permitted which does not comply with these terms. 